September $2000 \quad$ • NREL/SR-520-28989

\title{
Comprehensive Research on Stability of Amorphous Silicon and Alloy Materials and Devices
}

V.K. Dalal, K. Han, T. Maxson, R. Girvan, S. Kaushal, S. DeBoer, E. Ping, and S. Haroon lowa State University Ames, lowa

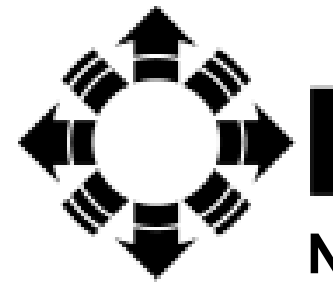

National Renewable Energy Laboratory

1617 Cole Boulevard

Golden, Colorado 80401-3393

NREL is a U.S. Department of Energy Laboratory

Operated by Midwest Research Institute $\bullet$ Battelle $\bullet$ Bechtel

Contract No. DE-AC36-99-G010337 


\section{Comprehensive Research on Stability of Amorphous Silicon and Alloy Materials and Devices}

V.K. Dalal, K. Han, T. Maxson, R. Girvan, S. Kaushal, S. DeBoer, E. Ping, and S. Haroon lowa State University Ames, lowa

NREL Technical Monitor: B. von Roedern

Prepared under Subcontract No. XAN-4-13318-08

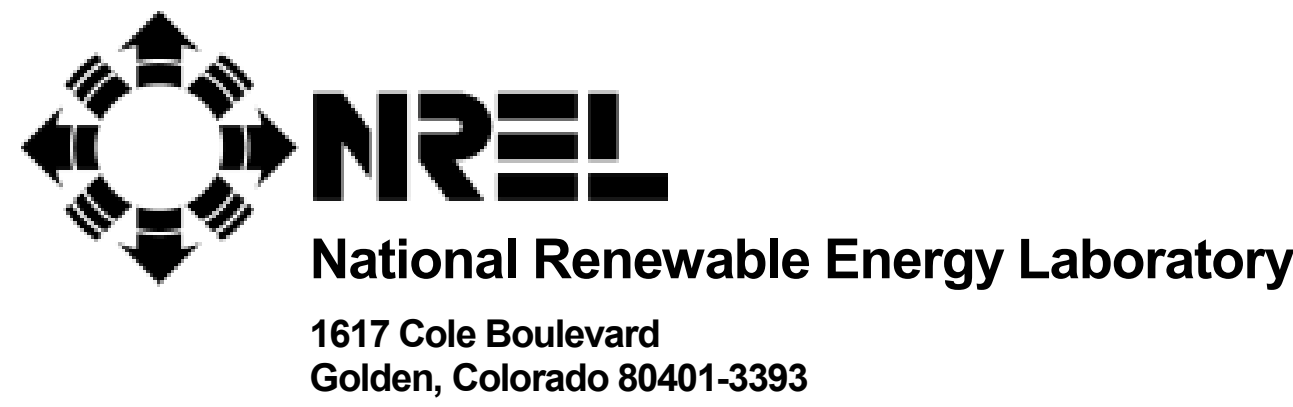

NREL is a U.S. Department of Energy Laboratory Operated by Midwest Research Institute • Battelle • Bechtel

Contract No. DE-AC36-99-G010337 


\section{NOTICE}

This report was prepared as an account of work sponsored by an agency of the United States government. Neither the United States government nor any agency thereof, nor any of their employees, makes any warranty, express or implied, or assumes any legal liability or responsibility for the accuracy, completeness, or usefulness of any information, apparatus, product, or process disclosed, or represents that its use would not infringe privately owned rights. Reference herein to any specific commercial product, process, or service by trade name, trademark, manufacturer, or otherwise does not necessarily constitute or imply its endorsement, recommendation, or favoring by the United States government or any agency thereof. The views and opinions of authors expressed herein do not necessarily state or reflect those of the United States government or any agency thereof.

Available electronically at http://www.doe.gov/bridge

Available for a processing fee to U.S. Department of Energy

and its contractors, in paper, from:

U.S. Department of Energy

Office of Scientific and Technical Information

P.O. Box 62

Oak Ridge, TN 37831-0062

phone: 865.576.8401

fax: 865.576.5728

email: reports@adonis.osti.gov

Available for sale to the public, in paper, from:

U.S. Department of Commerce

National Technical Information Service

5285 Port Royal Road

Springfield, VA 22161

phone: 800.553.6847

fax: 703.605.6900

email: orders@ntis.fedworld.gov

online ordering: http://www.ntis.gov/ordering.htm

Printed on paper containing at least $50 \%$ wastepaper, including $20 \%$ postconsumer waste 


\section{Table of Contents}

Abstract 3

Chapter I. Research on a-Si Materials and Devices 5

I.1 Introduction 5

I.2 Considerations about growth chemistry 5

I.3 Use of ECR reactor as a controlled plasma tool 9

I.4 Single junction device growth and results 9

$\begin{array}{lll}\text { I.5 Tandem junction device growth and results } & 26\end{array}$

$\begin{array}{ll}\text { I.6 Conclusions from a-Si:H research } & 26\end{array}$

Chapter II. Research on a-(Si,Ge) materials and devices 30

$\begin{array}{lll}\text { II.1 Introduction } & 30\end{array}$

$\begin{array}{lll}\text { II.2 Reactor system } & 31\end{array}$

II.3 Properties of films grown using Helium 31

II.4 Properties of films grown using Hydrogen 34

II.5 Possible explanation for pressure results 46

II.6 Results on devices in a-(Si,Ge):H 46

II.7 Conclusions from a-(Si,Ge) research 54

Chapter III. List of Publications resulting from this work 55

Chapter IV. Graduate student education $\quad 57$

$\begin{array}{lr}\text { Chapter V. References } & 58\end{array}$ 


\begin{abstract}
In this report, we describe the work done to improve the material and device properties of a-Si:H and a-(Si,Ge):H alloys prepared using ECR plasma deposition and to understand the growth chemistry. The following major results were obtained.

1. Influence of plasma chemistry on properties and stability of a-Si:H single junction solar cells. We discovered that plasma chemistry played a major role in improving the stability of single junction a-Si:H solar cells. While good devices could be made with either He or Hydrogen as the plasma gas in the ECR reactor, only the use of hydrogen(H-ECR process) led to improved stability. We postulate that this result arises from the fact that hydrogen plays three major roles in growth, namely radical selection, surface homogenization, and etching during growth. The combination of these effects may lead to a better micro-structure during growth, and hence, to better stability. Using appropriate plasma chemistry, we were able to make good cells with excellent stability.
\end{abstract}

2. Fabrication of good quality tandem junction cells. We made tandem junction a-Si/a-Si cells with excellent voltages and fill factors using the H-ECR process. We developed a unique gradedgap tunnel junction to improve the ohmic contact between the top and the bottom cells. The stability of these cells was also found to be excellent.

3. Growth of high quality a-( $\mathrm{Si}, \mathrm{Ge}): \mathrm{H}$ films using the ECR deposition process. We produced high quality a-(Si,Ge):H films using both $\mathrm{H}-\mathrm{ECR}$ and $\mathrm{He}-\mathrm{ECR}$ processes. The quality was better than that of glow discharge produced a-( $\mathrm{Si}, \mathrm{Ge}): \mathrm{H}$. We discovered that the plasma chemistry was even more important in producing good a- $(\mathrm{Si}, \mathrm{Ge}): \mathrm{H}$ films than was the case for a-Si:H. In particular, ion bombardment seemed to play a major role in producing good films. Conditions that led to a lower flux of $\mathrm{H}$ ions and radicals produced films which were significantly more defective. It is not clear from the data that ion energies per se were instrumental in improving the material properties; it may well be that the transfer of momentum to germane radicals at the surface by ion bombardment may be playing a role in improving the material properties.

4. Fabrication of single junction devices in a-( $\mathrm{Si}, \mathrm{Ge}): \mathrm{H}$ for diagnosing the material. We did a systematic study of the device-related properties of a-( $\mathrm{Si}, \mathrm{Ge}): \mathrm{H}$ materials by making diagnostic single junction devices. Hole mobility-lifetime products were measured in these devices using the quantum efficiency-voltage spectroscopy technique. In agreement with the results from the studies on film properties, it was found that the mobility-lifetime product of holes also depended on plasma chemistry, with conditions that had increased $\mathrm{H}$ ion and radical flux and bombardment producing device- materials with superior properties. The best material was produced at low pressures with H-ECR discharge.

5. Graded gap cells in a-(Si,Ge):H. Good devices were produced using a graded-gap I layer. 
In summary, the most important finding from our research has been that plasma chemistry plays a very important role in determining the properties of the materials, particularly the properties of the a-(Si,Ge):H alloy system. Even in a-Si:H, plasma chemistry plays a role in determining stability. This result suggests that by deliberately changing the chemistry of deposition, one may be able to further improve the a-( $\mathrm{Si}, \mathrm{Ge}): \mathrm{H}$ materials system and make its properties comparable to the properties of a-Si:H. The ECR reactor has proved to be a very useful chemical tool, with excellent control over growth chemistry. 


\section{Chapter I}

\section{$\underline{\text { Research on a-Si:H materials and devices }}$}

\section{I.1 Introduction}

a-Si:H is an important photovoltaic material. In the previous report[1], we had described our work on fabricating high quality a-Si:H materials and devices using the ECR growth technique. We had shown that it was possible to make high quality materials in a-Si:H at higher than normal temperatures using a Hydrogen diluted remote, reactive ECR discharge[H-ECR process]. The presence of excess hydrogen allowed one to use higher temperatures [350-375 C] since excess hydrogen prevented out-diffusion of hydrogen from the material at higher temperatures. We had shown that the stability of these materials was excellent, significantly better than the stability of standard glow discharge deposited a-Si:H [2].

We had also shown that one could make decent superstrate- type devices on tin oxide/glass substrates using the H-ECR process.[3]. The fill factors of these devices were in the $65 \%$ range. In the current report, we describe extensions of this work to substrate-type devices, and also describe some significant stability results on ECR- a-Si:H devices.

\section{I.2. Some considerations about growth chemistry}

An intriguing part of the a-Si:H story has always been the tremendous variability of material properties of a-Si:H. Even when a standard deposition technique, such as RF glow discharge deposition, is used, one finds a variability in stability properties of the material, and even in $\mathrm{H}$ content, depending on exactly how the material is made. In this section, we briefly describe some of the chemical considerations relating to the growth of the material and how they may influence the quality of the material.

It is well known that during plasma deposition of a-Si:H, a number of radicals are generated by the plasma. Among these are $\mathrm{SiH} 3, \mathrm{SiH} 2, \mathrm{SiH}$ etc. In addition, $\mathrm{H}$ is generated by decomposition of silane, or of hydrogen molecule if hydrogen is included as a diluent gas. The standard growth model, first enunciated by Gallagher[4], states that the dominant radical leading to the growth of films is $\mathrm{SiH} 3$, because of its non-reactivity with silane, as opposed to the reactivity of $\mathrm{SiH} 2$ with silane. However, a smaller percentage of $\mathrm{SiH} 2$ may be present in the reaction zone. Kushner estimated that the ratio of $\mathrm{SiH} 2 / \mathrm{SiH} 3$ is about $10 \%$.[5]. Some others have come up with higher estimates of this ratio. Clearly, then, it is possible that some finite, non-negligible percentage of radicals present during growth is $\mathrm{SiH} 2$, in addition to the dominant radical, $\mathrm{SiH} 3$.

The presence of more than one radical complicates the growth chemistry. Consider a Si surface, with dangling bonds, waiting to accept an electron at each dangling bond site. If only $\mathrm{SiH} 3$ were present in the discharge, it would bond into this site, and give rise to a surface which was passivated. See Fig. 1.1. From now on, it would not be possible to form another bond, and growth would cease. Clearly, then, the surface hydrogen has to be abstracted somehow. Two 
ways of doing this is with a $\mathrm{H}$ atom, forming a $\mathrm{H} 2$ molecule, or by a $\mathrm{SiH} 3$ radical, forming a silane molecule. Clearly, these two reactions have very different abstraction rates. Thus, even in the presence of only one radical in the plasma, a prescription exists for non-homogeneous growth.

Now, if more than one radical were present, say $\mathrm{SiH} 2$ and $\mathrm{SiH} 3$, then the surface looks very different after insertion. One site may have $\mathrm{SiH} 3$ inserted, with a resultant passive bond site, and another may have $\mathrm{SiH} 2$ inserted, with a resultant active bond site( a site which can accept another radical). This is a prescription for very non-homogeneous growth, particularly at the low temperatures characteristic of a-Si:H growth.

Thus, it should come as no surprise that the standard a-Si:H is not homogeneous, and that its microstructure is full of voids, small and large.[6]. And this microstructure depends on how one grows the material. As we change the material deposition conditions, we change the ion bombardment on the surface, we change the production and reaction rates of different radicals etc. As an example, if one were to use very low pressures, then $\mathrm{SiH} 2$ would not have an opportunity to react with silane, and therefore, the fraction of $\mathrm{SiH} 2$ relative to $\mathrm{SiH} 3$ may increase. Similarly, there would be little production of higher order silanes, such as Si2H6 at low pressures.

A particularly interesting aspect is the dilution effect of hydrogen in the discharge. Experimentally, one finds that having significant dilution of hydrogen (10:1 or greater) helps in improving the stability of materials and devices.[7]. The question is why. Considerations of growth chemistry provide the answer. At high hydrogen dilution, four effects take place.

1. Radical selection. In addition to the production of $\mathrm{SiH} 3$ by electron impact of silane in the plasma, $\mathrm{H}$ can also produce $\mathrm{SiH} 3$ through the reaction:

$\mathrm{H}+\mathrm{SiH} 4=\mathrm{H} 2+\mathrm{SiH} 3$.

Thus, the presence of significant hydrogen dilution, when combined with the long mean free path of atomic hydrogen, can lead to a significant increase in the ratio of $\mathrm{SiH} 3$ to $\mathrm{SiH}$. This is entirely beneficial for film growth, because it reduces one aspect of non-homogeneous film growth. We call this mechanism radical selection.

2. Surface homogenization. During growth, at high dilution, the most likely reaction after radical insertion into an active bond is removal of surface hydrogen by atomic hydrogen. Thus, all sites will have their hydrogen removed by reacting with another hydrogen, as opposed to some sites having it removed by interacting with silyl radical. Thus, the presence of a high density of atomic hydrogen results in homogenization of the surface, both in surface being bonded with hydrogen at all sites, independent of which radical inserted itself into the lattice, and in removal of this bonded hydrogen by another hydrogen. See Fig. 1.2. This surface homogenization, in turn, promotes homogeneous growth and reduces clusters and voids, as is seen experimentally in postgrowth studies. The hydrogen abstraction reaction by another hydrogen has been well proven by the work of Parsons et al.[8].

3. Homogenization due to higher hydrogen radical flux. Since increasing the hydrogen dilution necessitates increasing the power in the discharge to achieve reasonable growth rates, the flux 


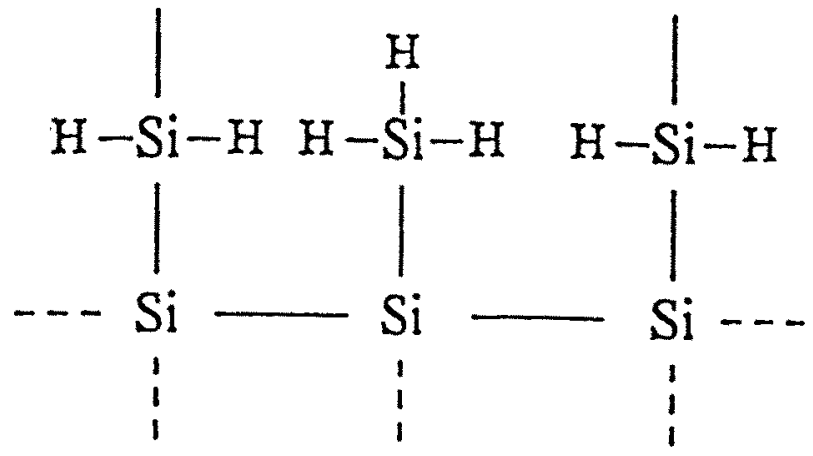

\section{A non-homogeneous surface in the absence of $\mathrm{H}$ dilution}

Fig. 1.1 Schematic diagram showing how having different radicals present during deposition leads to the formation of both active and passive sites on the surface, leading to non- homogeneous growth 


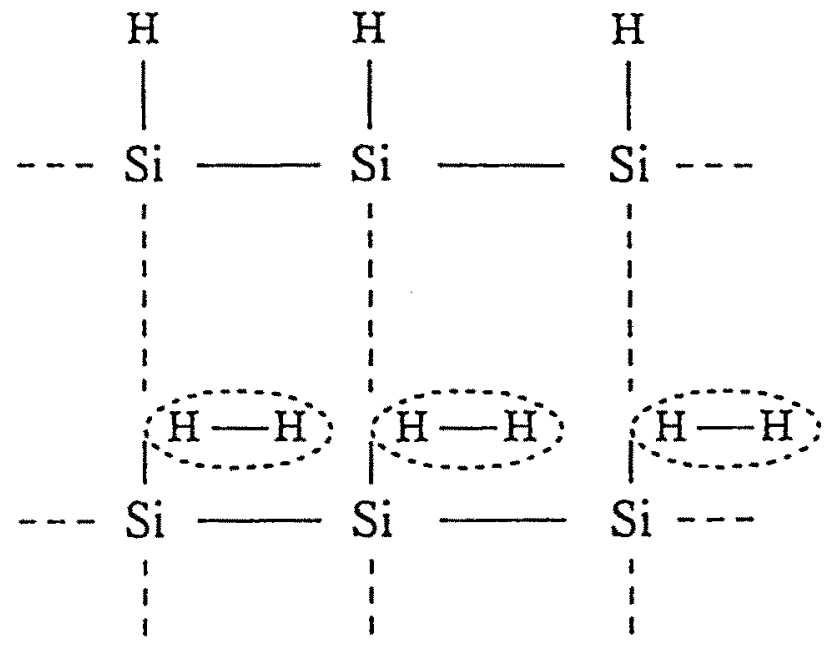

Fig. 1.2 Schematic diagram showing how the presence of significant atomic $\mathrm{H}$ during growth homogenizes the surface, and also allows for the abstraction of surface $\mathrm{H}$ by atomic $\mathrm{H}$ 
density of $\mathrm{H}$ radicals and ions impinging on the substrate also increases when hydrogen is used as a diluent. The increased ion density, and perhaps, increased ion energies, provide additional mobility to radicals on the surface, thereby promoting more homogeneous, cluster-free growth.

4. Etching during growth. Finally, hydrogen, being highly reactive, etches the material during growth. Hydrogen penetrates a few layers deep into the material, and rearranges the bonds, etching away the poorly bonded Si atoms, thereby allowing for the growth of a more ordered structure. Indeed, in the extreme case, etching leads to crystallization of the film.

Thus, hydrogen plays very important and beneficial chemical and physical roles during deposition, and it should come as no surprise that a significant hydrogen dilution improves the stability of the material.

\section{I.3 The use of ECR reactor as a finely controlled plasma tool}

From the above discussion, it is clear that one wants to be able to control the properties of the plasma so that beneficial effects such as ion bombardment and etching during growth can be controlled. Also, one needs to use low pressures so that radical-radical reactions are minimized. The ECR reactor is an ideal tool for achieving these aims. The geometry of the reactor is shown in Fig. 1.3. Briefly, a beam of $\mathrm{H}$ or He ions and radicals is incident upon the growing surface, where silane is introduced. The electrons in the plasma, and hydrogen and helium, react with silane to produce the radicals which give rise to growth. The reactor can be operated at very low pressures, down to $1 \mathrm{mT}$ if need be, and the ion energies and flux depend upon the pressure and power.

Using this reactor, we have deposited high quality a-Si:H films in the past.[1].Based on the above discussion about how the film grows, it is not a surprise that the ECR reactor can produce good films, since all the ingredients needed for producing such films are present and can be controlled. In this report, we are primarily going to focus on the growth of devices.

\section{I.4 . Single Junction Device growth and Results}

\section{A. Superstrate type devices}

We have continued our previous work on superstrate type devices. The device geometry is shown in Fig. 1.4. It is a standard superstrate device geometry, with a p-a-(Si,C) layer, followed by a buffer layer, an i layer, and finally, an $\mathrm{n}$ layer. Al back contact finishes the device.

A major problem that we faced in making this device was diffusion of $\mathrm{B}$ from the p layer into the i layer, even though a $(\mathrm{Si}, \mathrm{C})$ buffer layer was used. B is known to diffuse rapidly, particularly at the higher temperatures characteristic of our growth. Diffusion of B would reduce the fill factor of the device, because of increased electron recombination at the $\mathrm{p}-\mathrm{i}$ interface. To reduce this $\mathrm{B}$ diffusion, we used a graded doping/graded gap $\mathrm{p}$ layer, as shown in Fig. 1.5. The $\mathrm{p}$ layer next to the i layer was lightly doped so as to reduce B diffusion. Using such techniques, we were able to make decent devices. A typical device I(V) curve is shown in Fig. 1.6. The fill factor is quite 


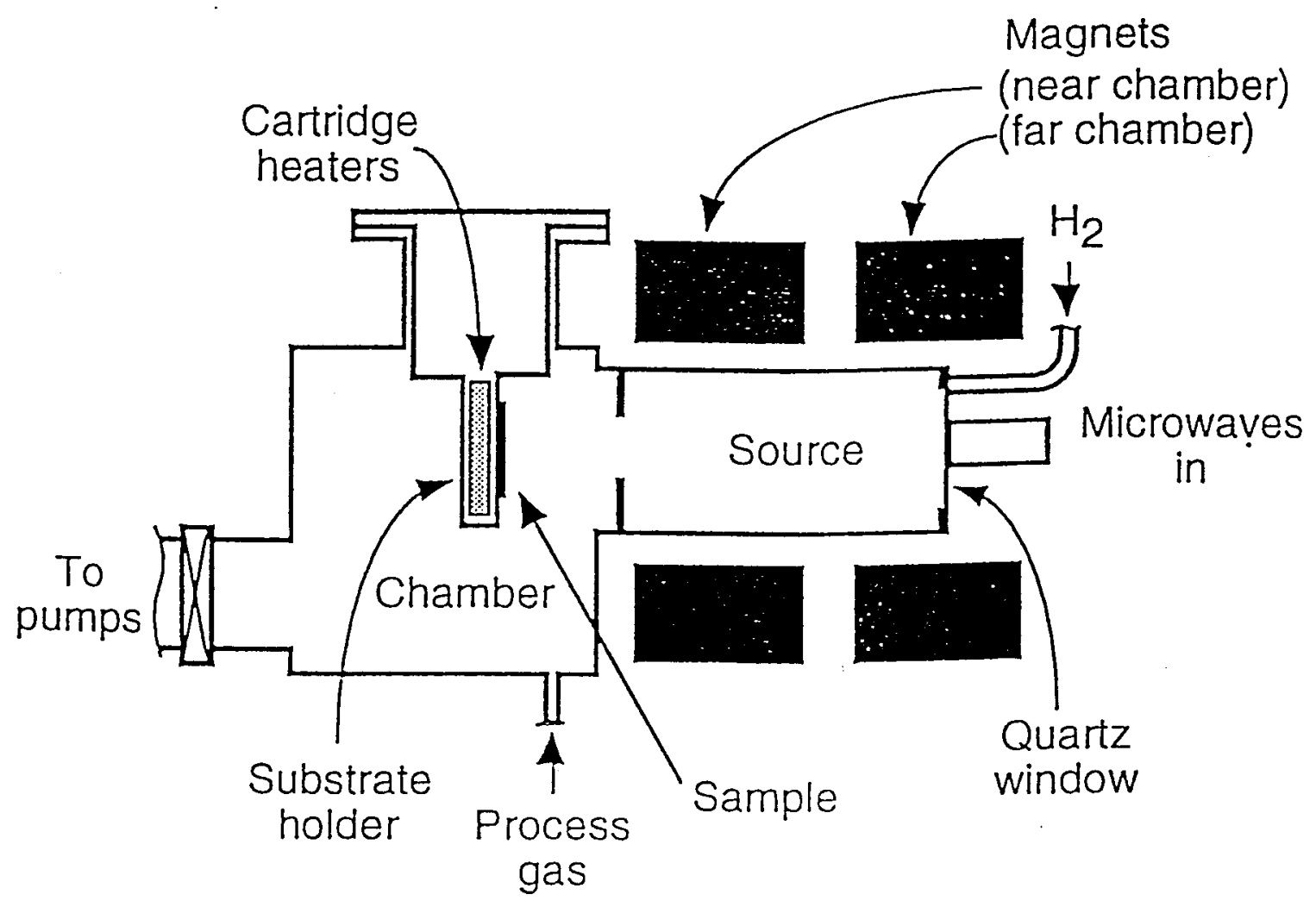

Fig. 1.3 Schematic diagram of the ECR Reactor 


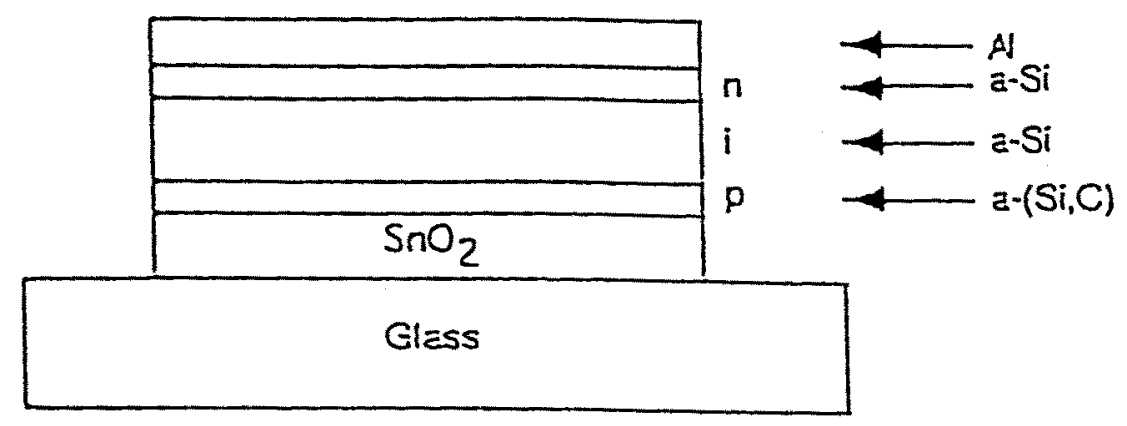

Fig. 1.4 Schematic diagram of the superstrate device structure 


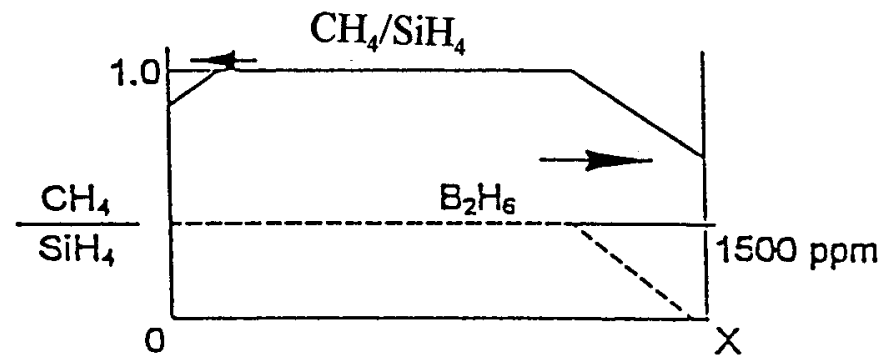

(A)

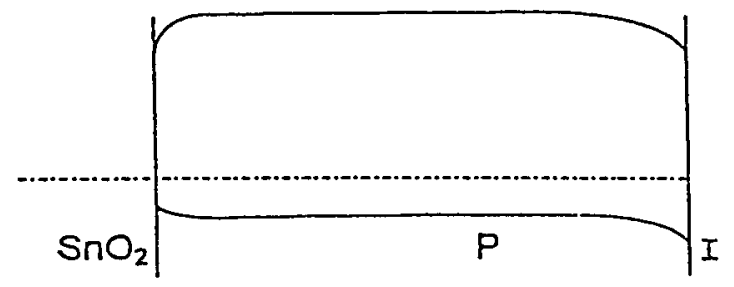

(6)

Fig. 1.5 (a) Diborane and methane grading in $\mathrm{p}$ layer (B) Band diagram of $p$ layer 

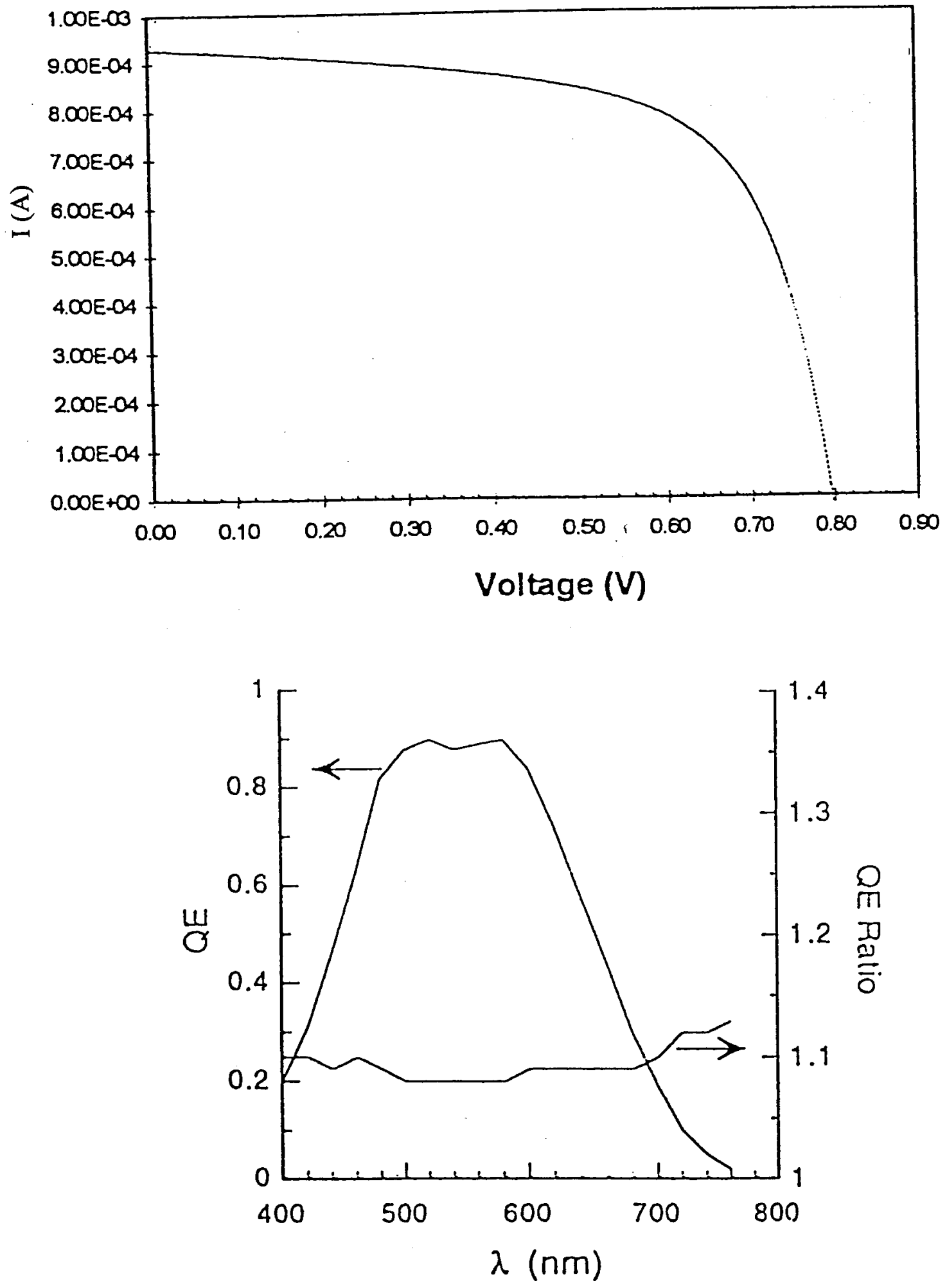

Fig. 1.6 I(V) curve, QE curve, and QE ratio curve for superstrate cell 
good, $66 \%$, and the voltage is about $0.8 \mathrm{~V}$. The current density is $13 \mathrm{~mA} / \mathrm{cm}^{2}$, for an efficiency of about $7.5 \%$. The thickness of the intrinsic layer was about $300 \mathrm{~nm}$.

We next measured the stability of this device under 2xsun intensity. As expected, the device showed excellent stability. See Fig. 1.7.

While these devices were good, we ran into problems when we tried to increase the open circuit voltage. It was never possible to achieve $\mathrm{V}_{\text {oc }}$ greater than about $0.8 \mathrm{~V}$, whereas we would normally expect voltages in the range of 0.85 to $0.9 \mathrm{~V}$. Also, since we were depositing directly on tin oxide substrates, it was difficult to make the p layer microcrystalline, which, perhaps, would have helped increase the voltage. Therefore, we decided to investigate the reverse structure, namely a substrate cell, where diffusion problems do not exist and the $p$ layer can be easily made microcrystalline.

\section{B. Substrate devices}

The basic geometry of the substrate device is shown in Fig. 1.8. The device is deposited directly on a rough stainless steel substrate, not electro-polished steel. To prevent shorts, a thick $(0.25$ micrometer) $n$ layer is first deposited in a glow discharge reactor, and the substrate is then transferred to the ECR reactor. There, a second $n$ layer is deposited, followed by a thorough purge and evacuate procedure. After the residual phosphine is purged from the reactor, a plasma etch is done to remove any $n$ layer from the walls of the rector, followed by deposition of a dummy i layer on the reactor walls. Following this procedure, the i layer is deposited,. The i layer is doped slightly with ppm B, as described earlier in film work. The $\mathrm{i}$ layer is followed by a $\mathrm{p}-\mathrm{i}$ buffer layer, which is graded gap a-(Si,C). The purpose of this graded gap layer is to prevent electron back diffusion towards the $\mathrm{p}-\mathrm{i}$ interface and subsequent recombination.[9 ].

Finally, the $\mathrm{p}$ layer is deposited. The $\mathrm{p}$ layer consists of a two-layer combination, an $\mathrm{a}-(\mathrm{Si}, \mathrm{C}) \mathrm{p}$ layer, followed by a microcrystalline $\mathrm{p}$-Si layer. The top microcrystalline layer tends to oxidize rapidly and sometimes leads to problems with ohmic contacts. To prevent such problems, sometimes, we cap off the microcrystalline $\mathrm{p}$ layer with a thin a-( $\mathrm{Si}, \mathrm{C}) \mathrm{p}$ layer.

Finally, ohmic contacts are provided with either semi-transparent $\mathrm{Cr}, 100 \mathrm{~A}$ thick, followed by a central Al bussbar to collect currents, or by ITO.

The results from some devices made using H-ECR process are shown in Fig. 1.9. The voltages have now increased to $0.84 \mathrm{~V}$ range, and the fill factors are in the $68 \%$ range. The $\mathrm{QE}$ curve for a device is shown in Fig. 1.10, and the corresponding QE ratio curve also in Fig. 1.10. A low QE ratio ( $\mathrm{QE}$ at $0 \mathrm{~V} / \mathrm{QE}$ at $+0.5 \mathrm{~V}$ ) across the entire wavelength range indicates that the collection efficiency of both electrons and holes is very good.[9]. Based on the QE data, we estimate the current density to be about $12.5 \mathrm{~mA} / \mathrm{cm}^{2}$, respectable given that there is no back reflector. The results of stability tests in these devices are shown in Fig. 1.11 Stability was measured under xenon lamp with a water filter. The cells were exposed to a focused illumination such that the intensity of sunlight going into the device was $200 \mathrm{~mW} / \mathrm{cm}^{2}$. The cells were kept at temperatures of between 50-60 C. The stability of the cells is shown to be excellent, with the fill factor degrading only about $5 \%$. 


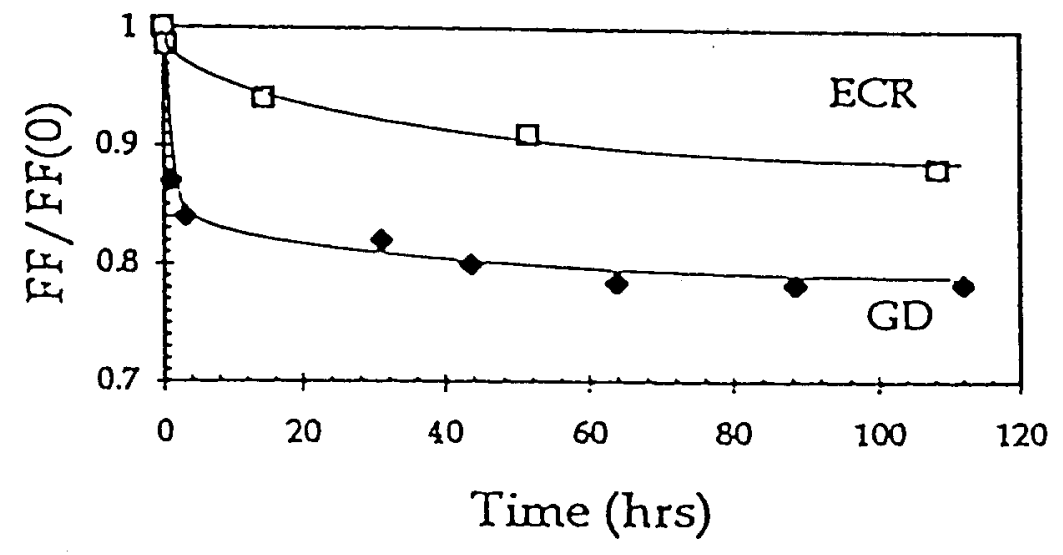

Fig. 1.7 Stability of ECR cell compared with stability of Glow discharge cell.

Each cell had the same initial fill factor( 0.66-0.68), and similar i layer thickness 


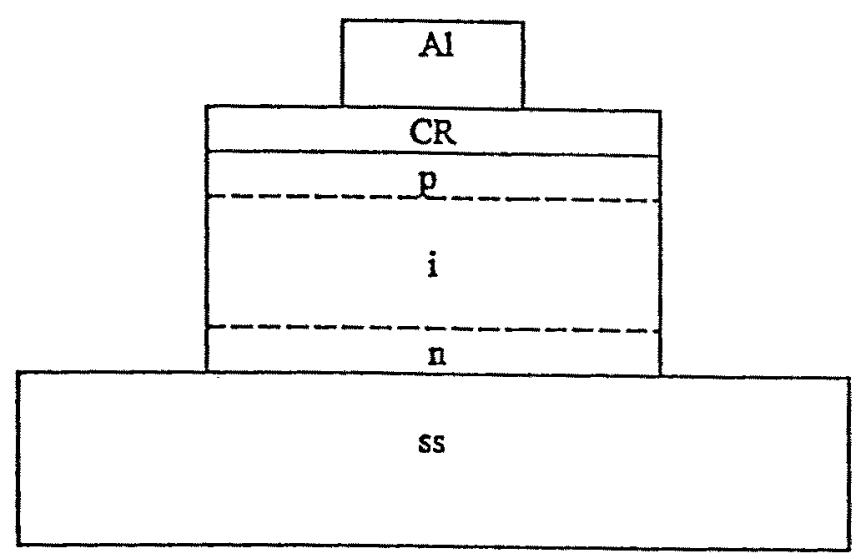

$\underline{\text { Fig. 1.8 }}$ Substrate device structure 


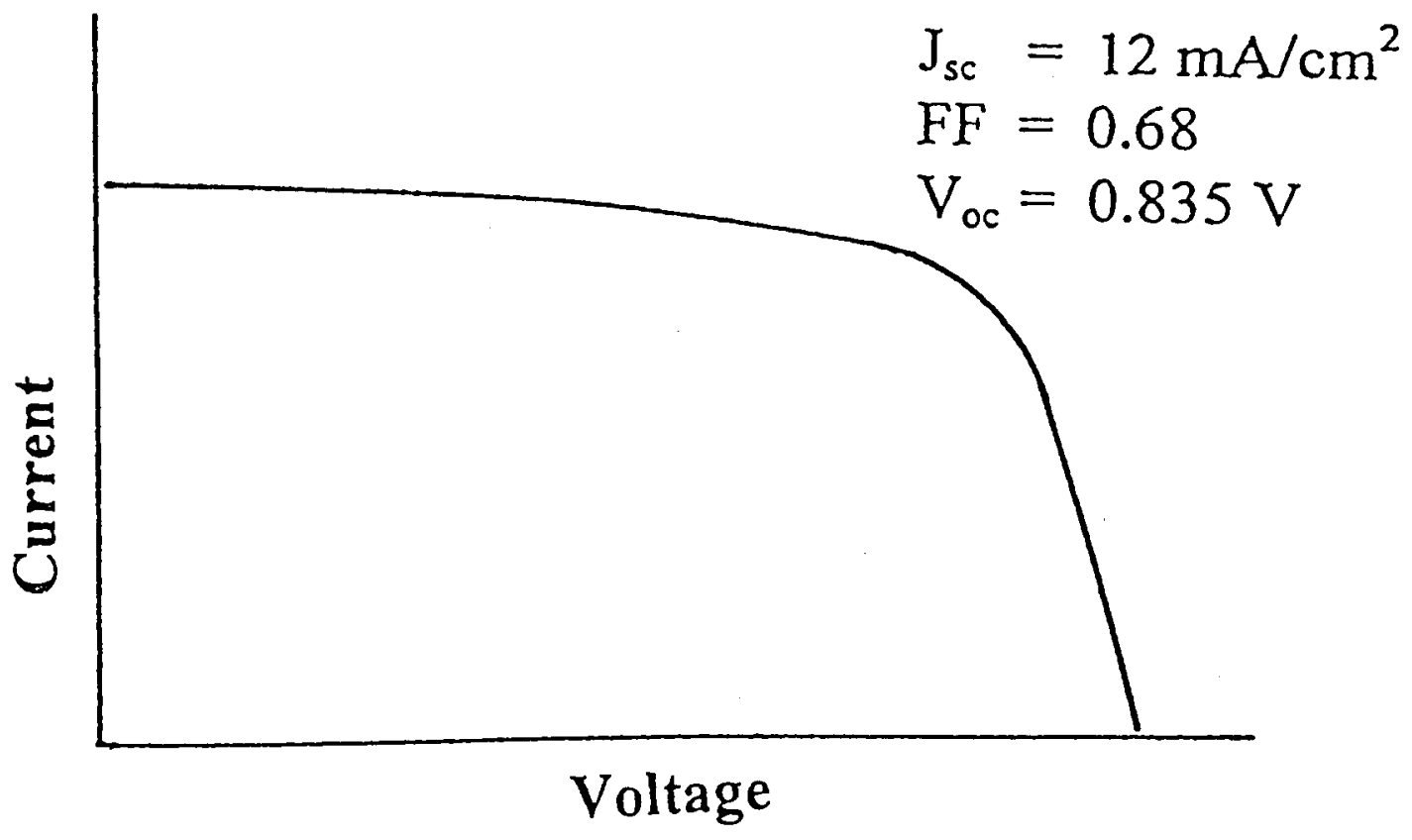

Fig. $1.9 \quad \mathrm{I}(\mathrm{V})$ curve for a substrate cell 


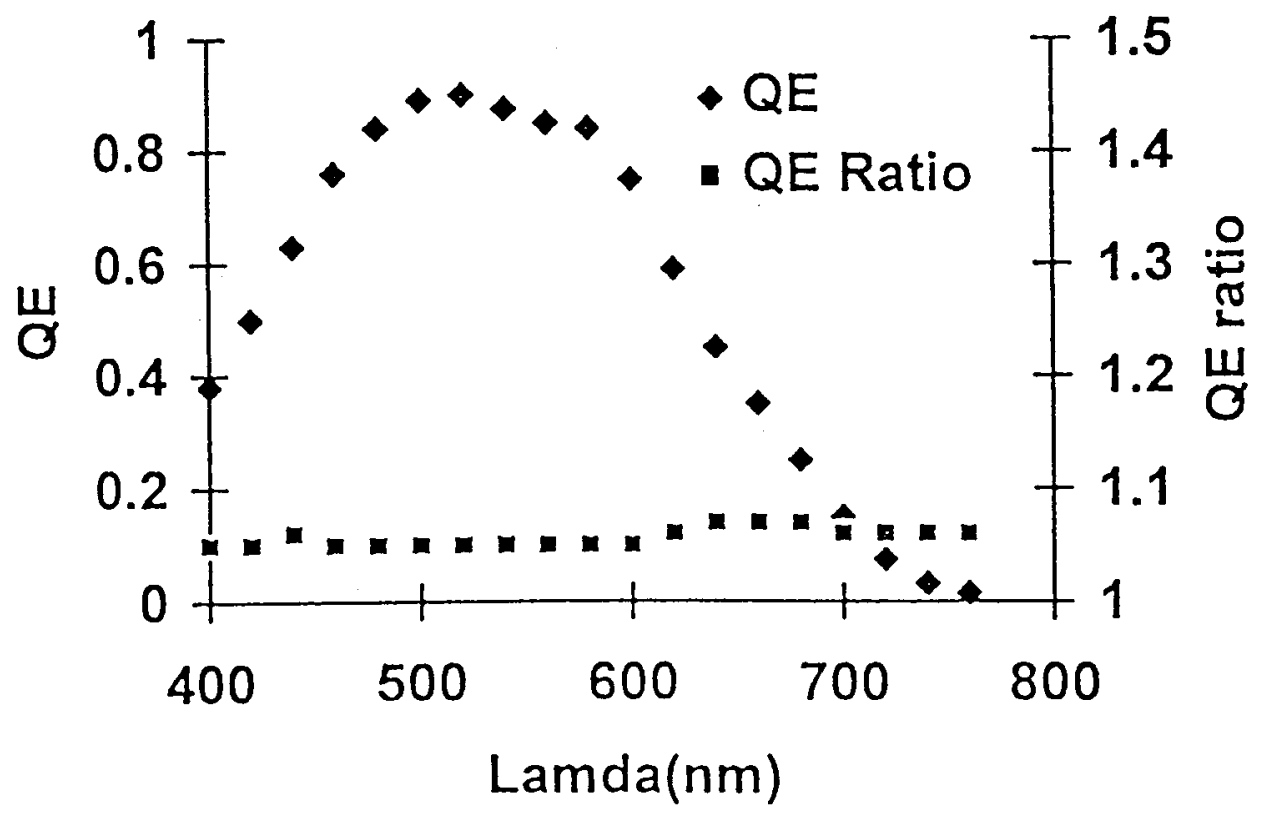

Fig. 1.10 QE and QE ratio curve for cell whose I(V) curve is in Fig. 1.9. A low value of $Q E$ ratio indicates good hole and electron collection 


\section{Degradation of Fill Factor of ECR Cell}

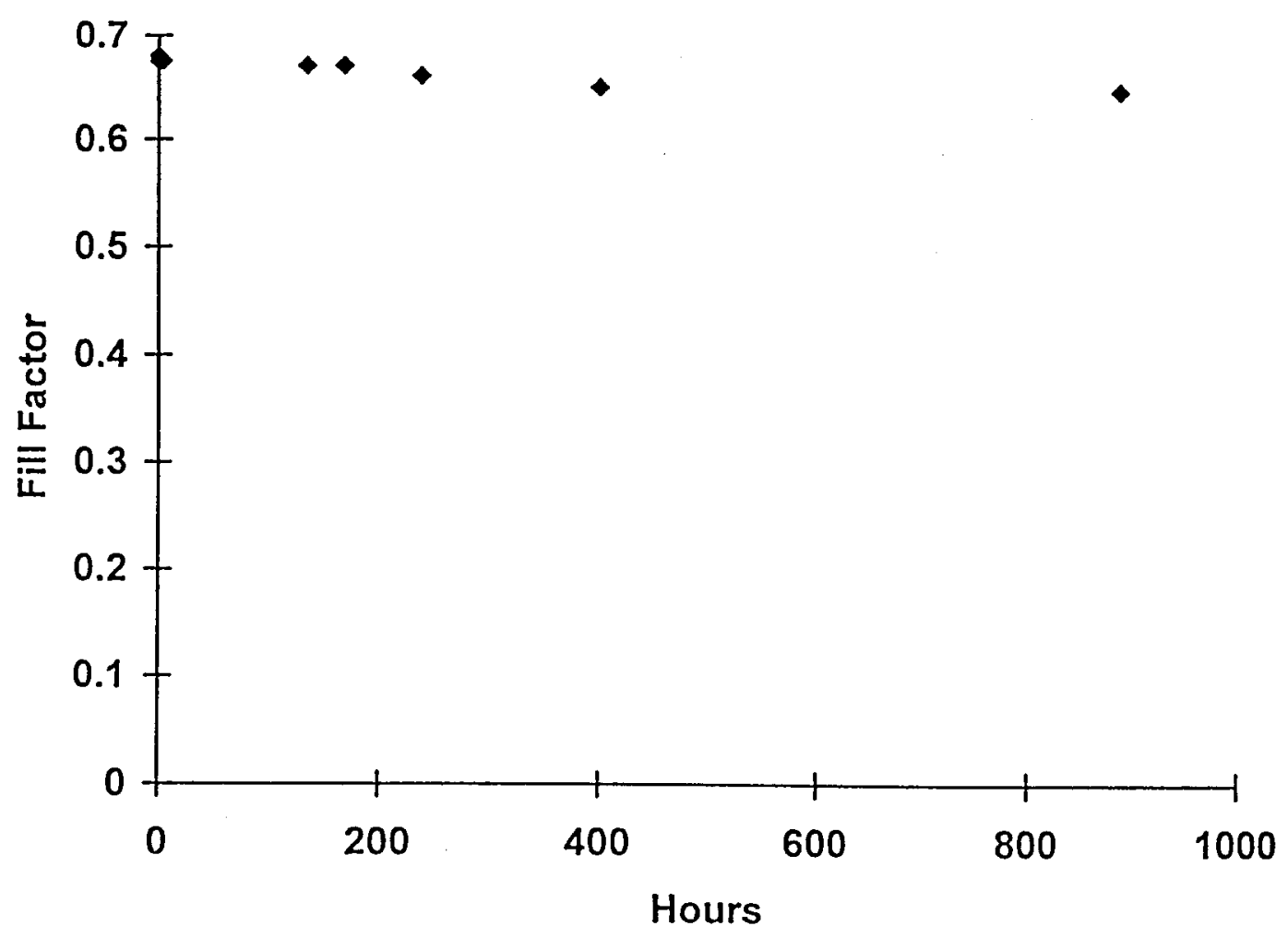

Fig. 1.11 Degradation in fill factor of H-ECR cell measured under 2 x Sun (xenon) illumination 
Thus, we have been able to deposit very high quality a-Si devices using the H-ECR process, with excellent stability.

\section{Devices made using the He-ECR process.}

Since we can make good films with either $\mathrm{He}$ or $\mathrm{H}$, we decided to study devices made using He. He does provide ion bombardment during growth; actually, it provides more ion bombardment than $\mathrm{H}$ does, since both the mass of $\mathrm{He}$ ions is larger, and the plasma potential for any given power is larger. See Fig. 1.12.

The results for films were similar to the films produced using H-ECR, and have been reported previously.[1 ]. A noteworthy result of this previous work was that the He-ECR films had a lower Tauc bandgap, about $1.67 \mathrm{eV}$, and a lower $\mathrm{H}$ content. The $\mathrm{H}$ content was only about 4-5\%, compared with 6-8\% for H-ECR films.

The devices were made in both the substrate and superstrate geometries. The superstrate results have been reported previously.[1,10 ]. The results for cells made in the substrate geometry are shown here in Fig. 1.13. The I(V) curve is quite good, with a high fill factor(0.72), and voltage $(0.81 \mathrm{~V})$. The $\mathrm{QE}$ results are shown in Fig. 1.14, along with the QE ratio results. From the QE data, we can conclude that the material indeed has good hole collection properties.

To see if the lower bandgap seen in the films was maintained in the devices, we compared the subgap QE data for a He-ECR device with the subgap QE data for a H-ECR device. The two devices had identical thicknesses of the I layer. The subgap QE, to a good approximation, is given by $\mathrm{QE}=[1-\mathrm{exp}-(\alpha \mathrm{t})]$, which becomes, for small $\alpha \mathrm{t}, \mathrm{QE} \sim \alpha \mathrm{t}$. Thus, if thicknesses are identical, by comparing the subgap QE for two different cells, we can compute the difference between their Tauc Gaps. Such a comparison for two cells mentioned above is shown in Fig. 1.15. There appears to be a shift in absorption curve to lower energies for the He-ECR device by about $40 \mathrm{meV}$, a shift similar to the one seen in the data on films. The Urbach energy of valence band tails measured from the curve is about $44 \mathrm{meV}$, indicating an excellent quality film, in accordance with the good fill factors reported above in Fig. 1.13.

\section{$\underline{\text { Results on stability of He-ECR cells }}$}

The stability of He-ECR cells was measured using the same protocol as for H-ECR cells. The stability of these cells is shown in Fig. 1.16, where the degradation in fill factor is shown for $\mathrm{H}$ ECR, He-ECR and a standard glow-discharge cell. All the cells had similar fill factors initially, and had approximately the same thickness of the i layer, about $300 \mathrm{~nm}$. Fig. 1.16 shows that in contrast to the H-ECR cell, the He-ECR cell degrades much more rapidly, with a degradation profile similar to the one for a glow discharge cell made without H-dilution.

This is a remarkable result, because it contradicts the conventional wisdom that materials with a lower H content degrade less. The H-ECR cell had a measurably higher $\mathrm{H}$ content than the HeECR cell, but it degraded much less than the He-ECR cell. One is forced to conclude that it is the chemical influence of hydrogen during growth which is critical for achieving better stability, and 


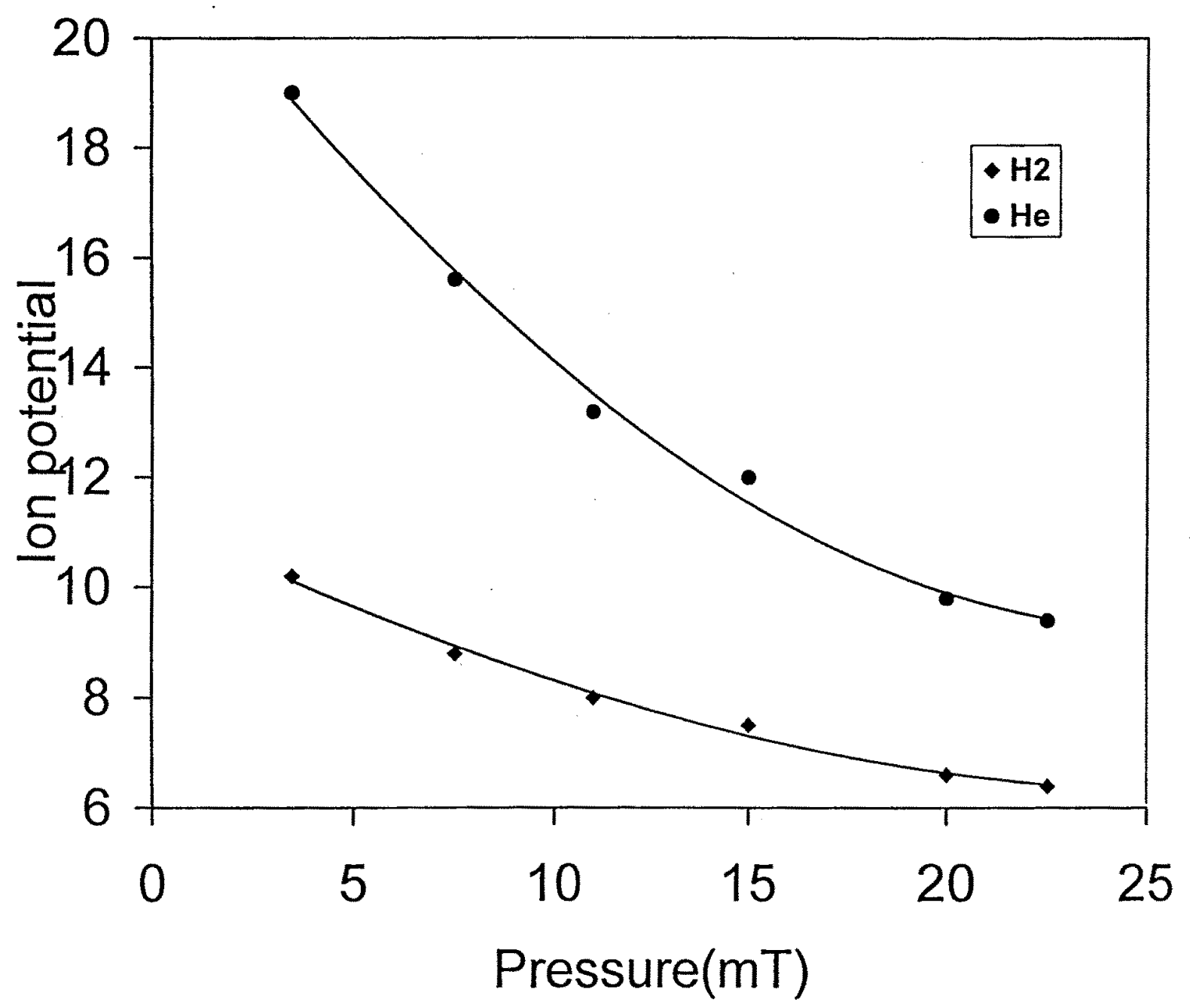

Fig. 1.12 Ion potentials in $\mathrm{H}$ and He plasmas 


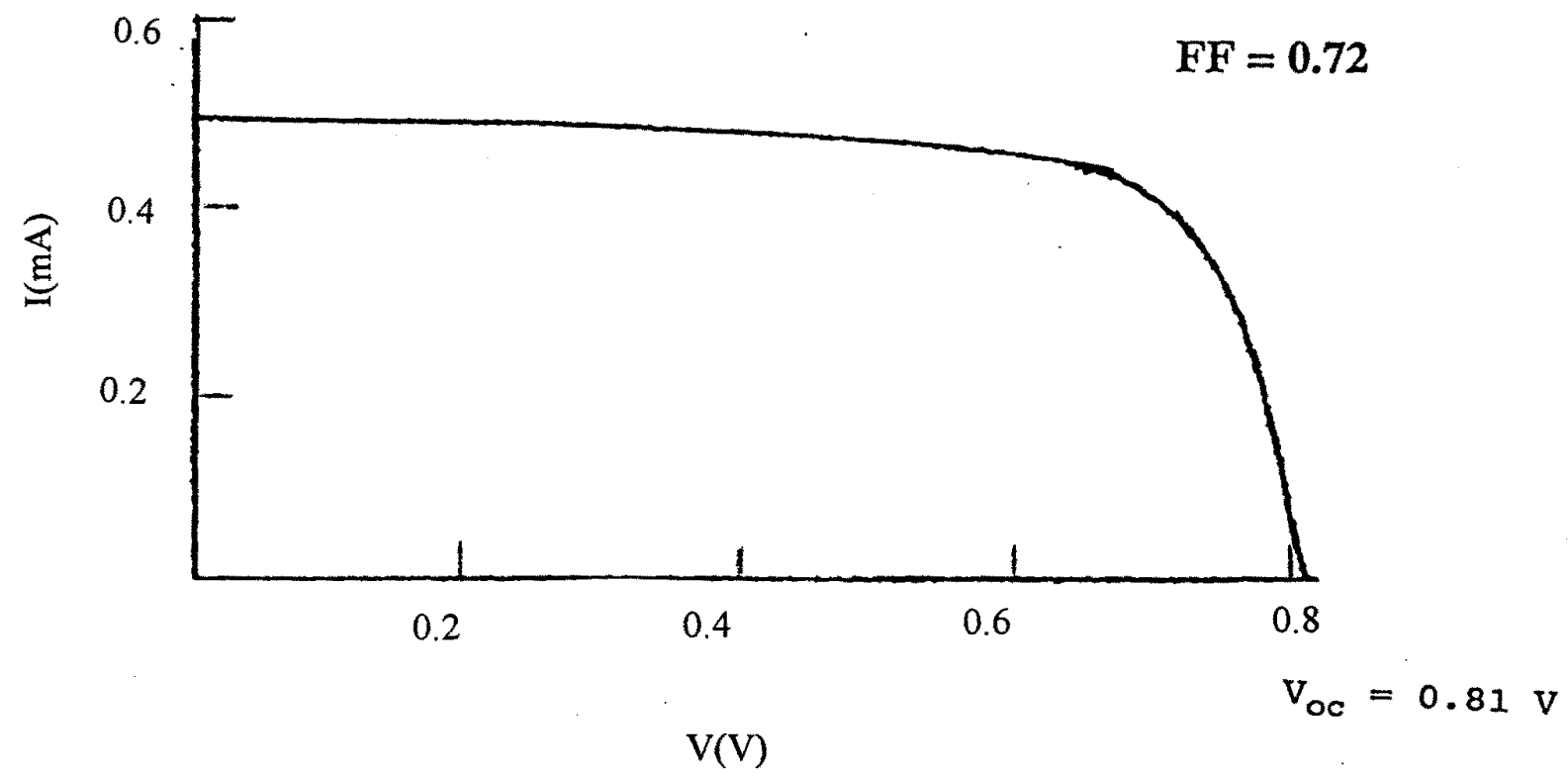

Fig. 1.13 $\quad \mathrm{I}(\mathrm{V})$ curve of He-ECR substrate device 

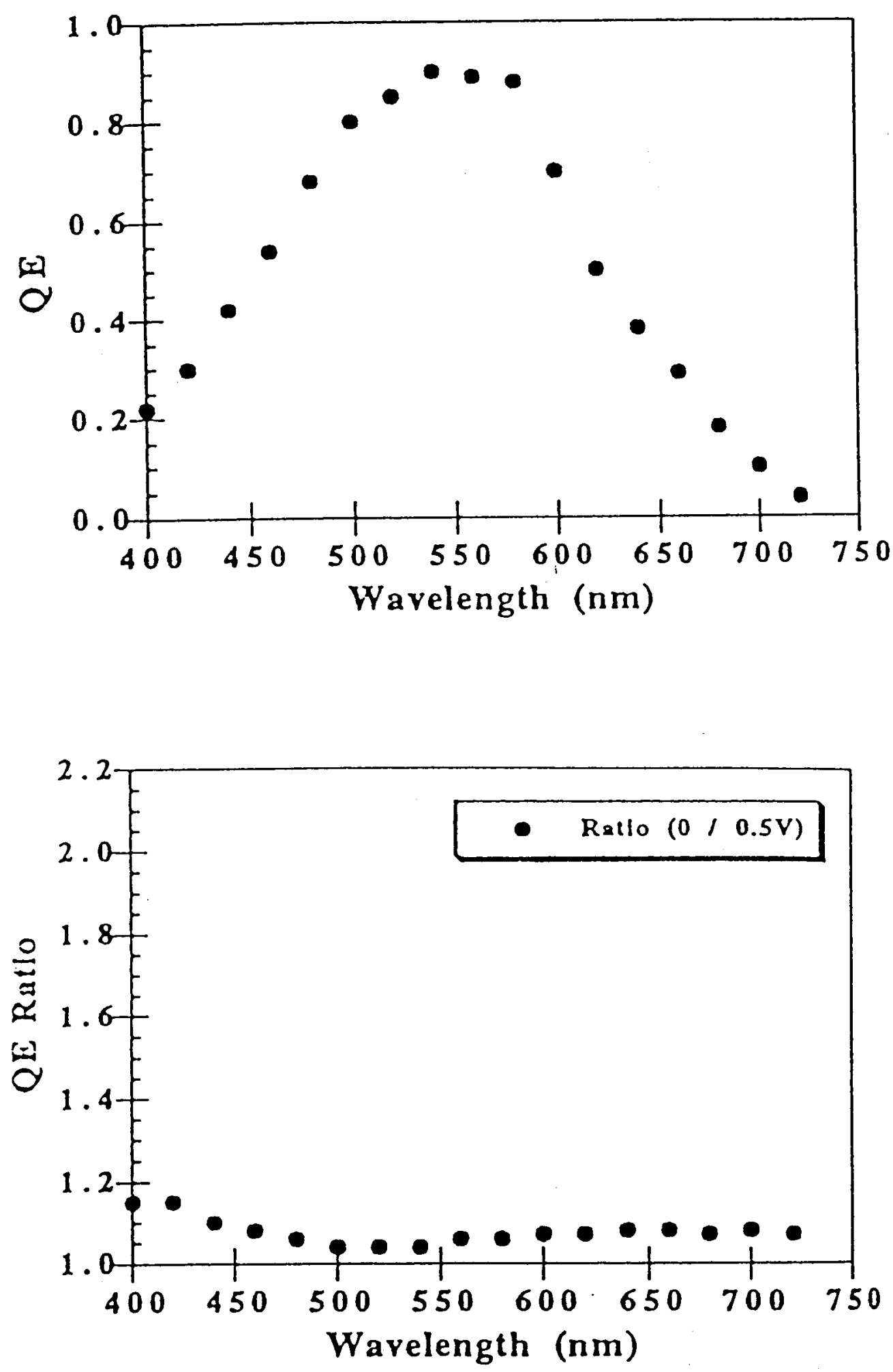

Fig. 1.14 QE and QE ratio curves for He-ECR cell 


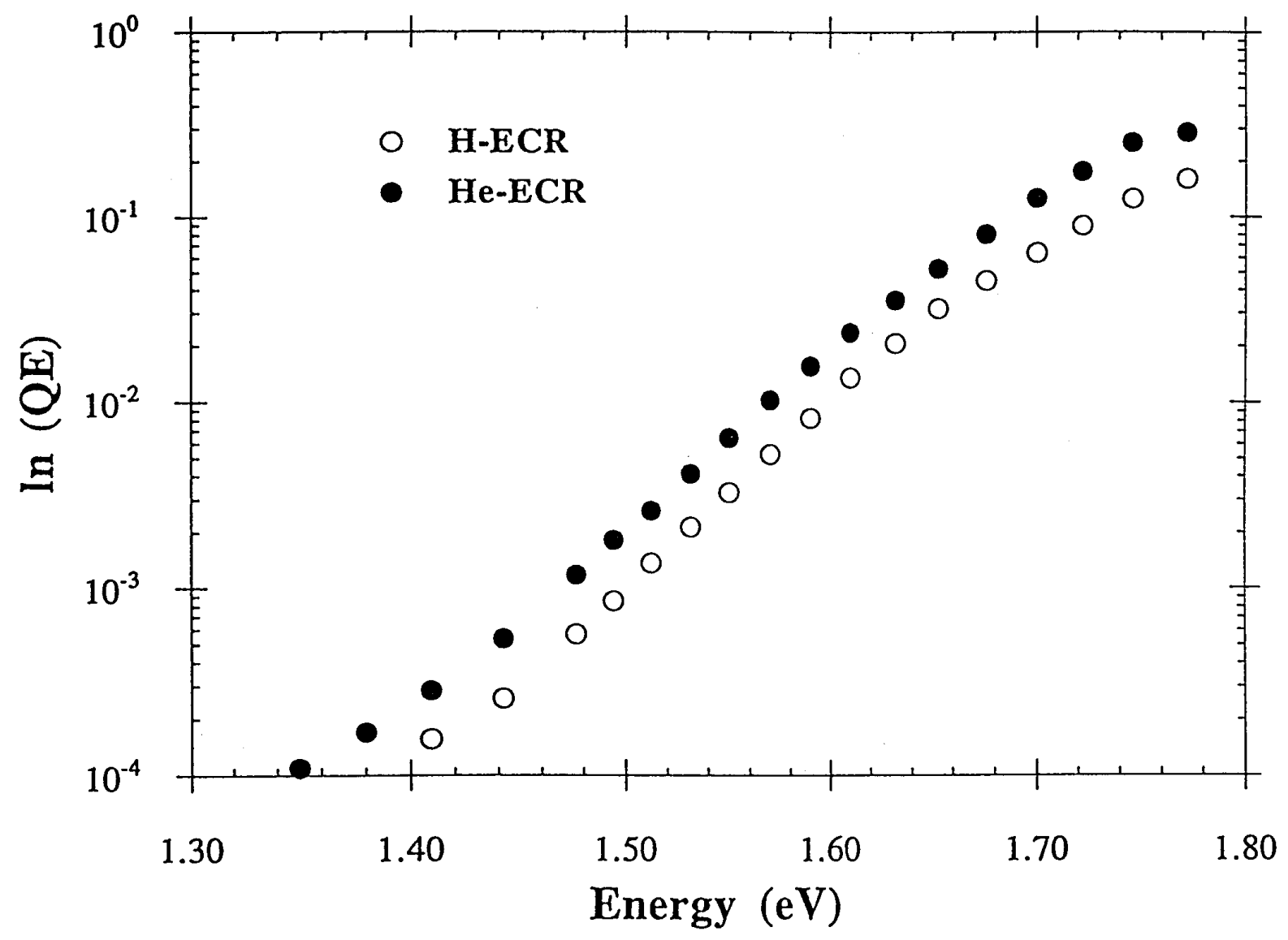

Fig. 1.15 Subgap QE of H-ECR and He-ECR devices. 


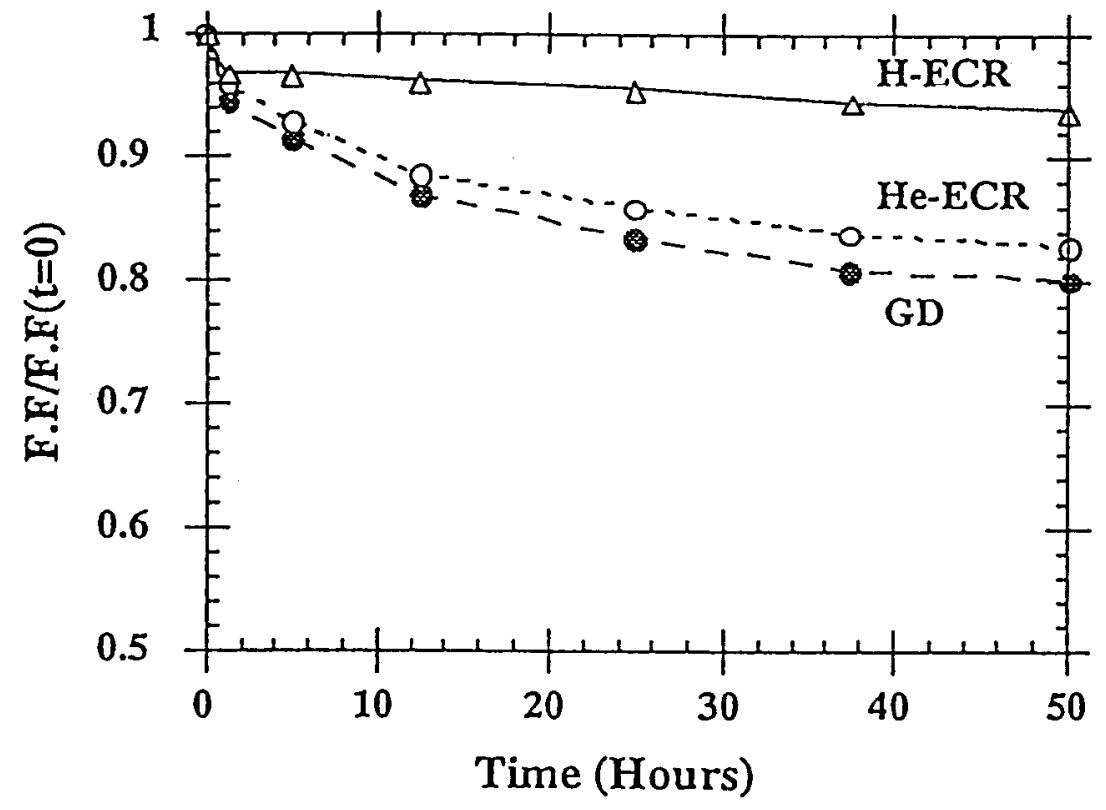

Fig. 1.16 Comparison of the degradation in fill factor of H-ECR, He-ECR and glow discharge devices. Each device had a similar i layer thickness $(300 \mathrm{~nm})$ and a similar initial fill factor $(0.68)$ 
not merely the $\mathrm{H}$ content. We have discussed above how $\mathrm{H}$ may influence the achievement of a more homogeneous film with better microstructure if it is present during growth.

\section{I.5 Tandem Junction Device Growth and Results}

Based on the success of the single junction devices, we decided to see if tandem junction a-Si/a$\mathrm{Si}$ devices could be made using the H-ECR process. The device fabrication process was similar to the one for substrate type devices, except that now we had to make two cells in a single chamber reactor. The bottom cell was made according to the prescription described above for single junction cells, except of course no Cr layer was used at the top. The p layer of the bottom cell was made from a-(Si,C), with the final $\mathrm{p}$ layer being graded on bandgap to achieve a lower bandgap. This was done to achieve a more efficient tunnel or recombination junction at the $\mathrm{p} / \mathrm{n}$ interface between the bottom and top cells, See Fig. 1.17. The top cell was also of p-I-n type, with the $n$ layer being deposited first on top of the previous cell's $p$ layer. Of course, extensive purges and plasma cleaning of the chamber were required between the $\mathrm{p}$ and the $\mathrm{n}$ layers, to reduce cross-contamination, as also after the second $\mathrm{n}$ layer to reduce $\mathrm{P}$ contamination of the top I layer. The top i layer was deposited at a lower temperature, about $275 \mathrm{C}$, so as to achieve a slightly higher bandgap. The thickness of the top i layer was about $700 \mathrm{~A}$, and of the bottom $\mathrm{i}$ layer, about $2600 \mathrm{~A}$.

The I(V) curve for a tandem cell is shown in Fig. 1.18. The fill factor is excellent, $>70 \%$, and the voltage, even with $\mathrm{Cr}$ contacts, is over $1.6 \mathrm{~V}$. It would be higher by about $60-70 \mathrm{mV}$ with ITO contacts.

The stability of the cell was tested using the protocol described earlier for single junction cells. The results are shown in Fig. 1.19. The degradation in fill factor is minimal, comparable to the results of the single junction H-ECR cells.

\section{$\underline{\text { I.6. Conclusions from a-Si:H research }}$}

Thus, we have successfully deposited high quality single and tandem junction cells using the HECR process and the stability has been shown to be excellent. He-ECR process also leads to good devices, but with poorer stability. Clearly, the chemistry of growth is very important, and we have the tool [ECR reactor] to be able to change this chemistry quite controllably. We can change the ion bombardment, and change the chemical reactivity, by introducing heavier ions, and by introducing chemical etchants such as $\mathrm{H}$ or $\mathrm{F}$ or $\mathrm{Cl}$ during growth. This flexibility will be pursued during the next contract to systematically improve the properties of the material and also to control $\mathrm{H}$ bonding and the bandgap. 


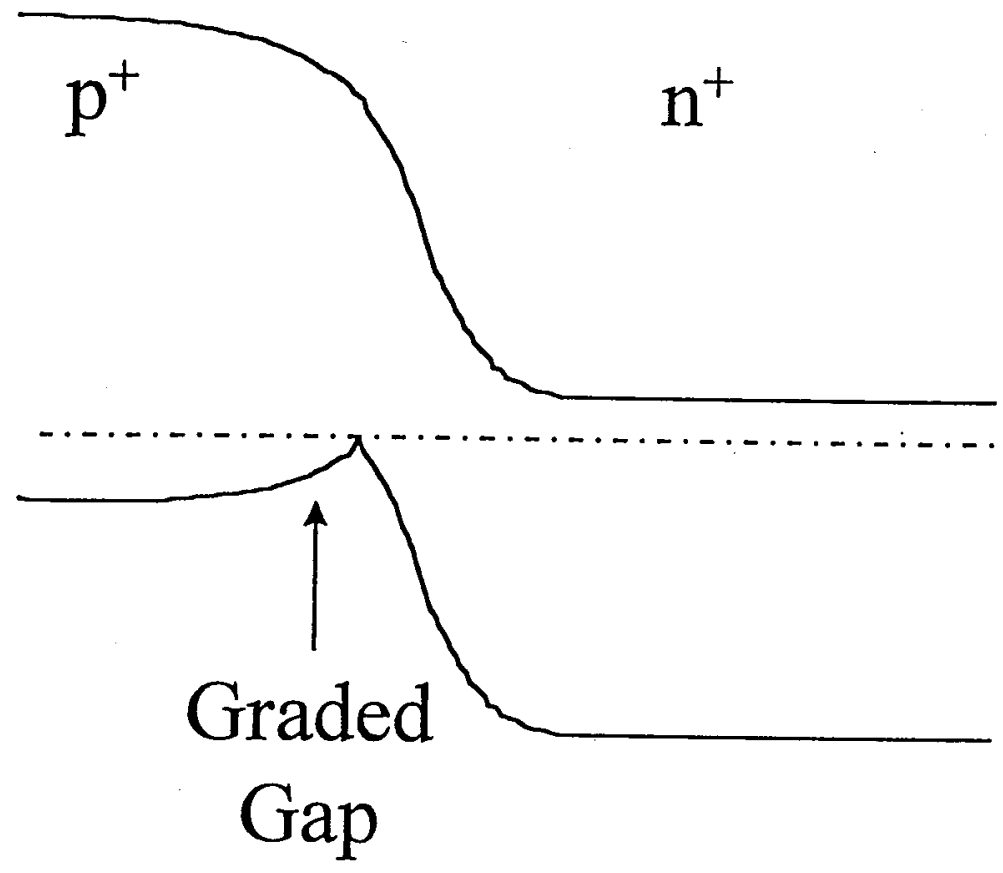

Fig. 1.17 A graded gap $\mathrm{p}$ layer structure used to improve tunneling between $\mathrm{n}$ and $\mathrm{p}$ layers in a tandem cell 


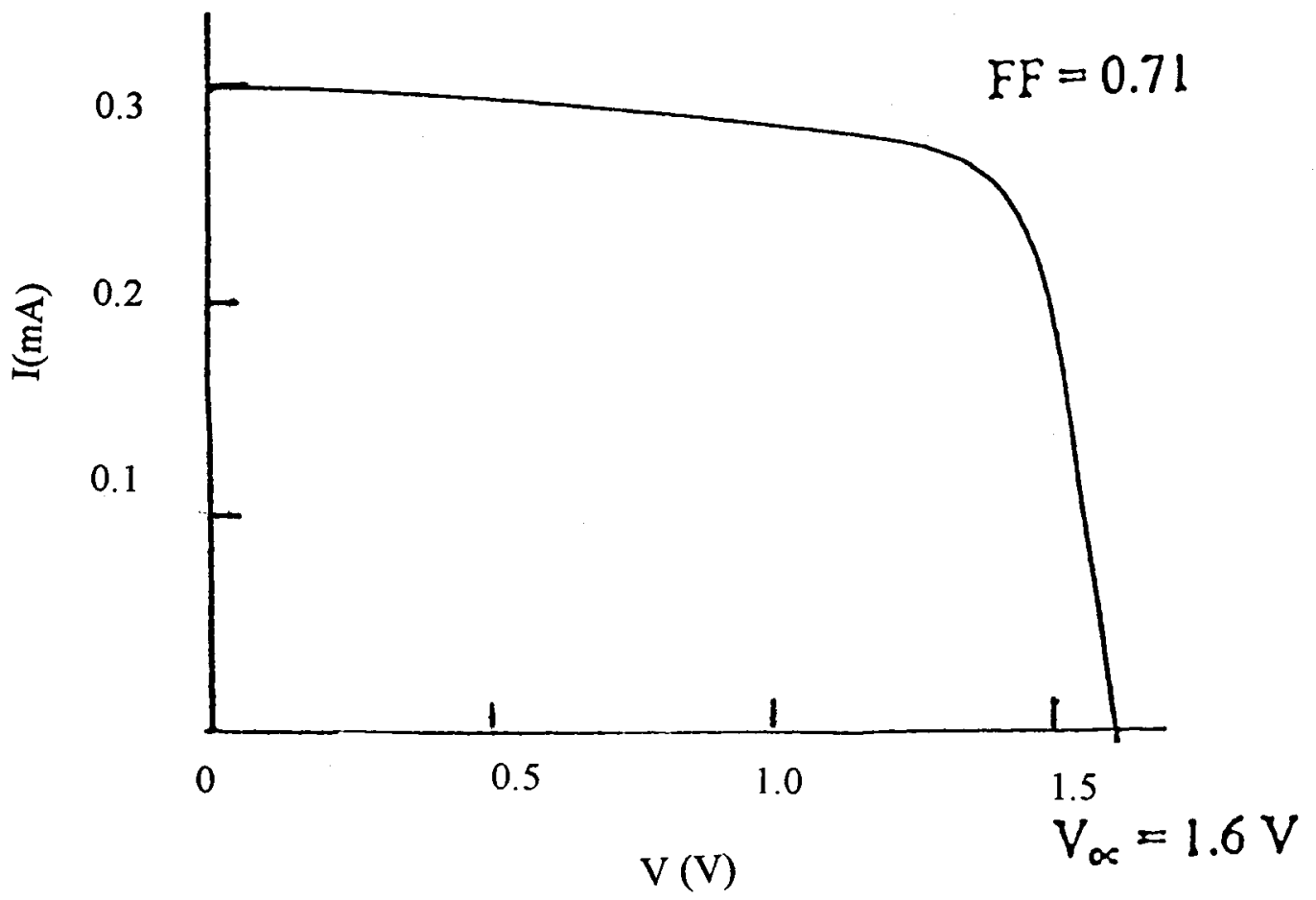

Fig. $1.18 \quad \mathrm{I}(\mathrm{V})$ curve of a tandem junction solar cell using the H-ECR process 
Fill factor of tandem cell ( 1 sun, $50 \mathrm{C}$ )

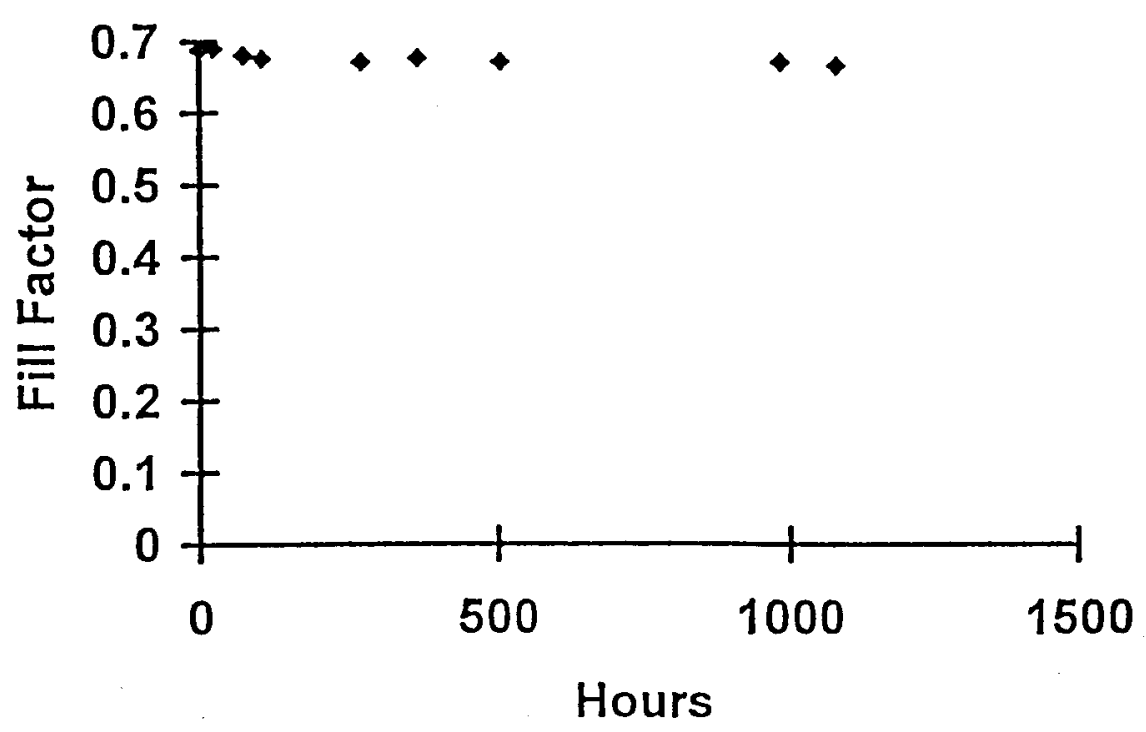

Fig. 1.19 Stability of tandem junction solar cell made using the ECR process 


\section{Chapter II.}

\section{$\underline{\text { Research on a-(Si,Ge) Materials and Devices }}$}

\section{II.1. Introduction}

a-(Si,Ge):H materials play a critical role in multi-junction cells made in a-Si based device systems.[11]. Ever since the earliest days of research on this material system, it has been recognized that the quality of a-(Si,Ge) materials is inferior to that of a-Si.[12-15]. There are fundamental reasons why the alloy material should be inferior to the non-alloyed materials. Among others, the alloy may be non-homogeneous, with clustered Ge-Ge and Si-Si bonds, as opposed to a random alloy with homogeneous Ge-Si composition. In addition, the very different bond energies of $\mathrm{Ge}-\mathrm{H}$ bond from $\mathrm{Si}-\mathrm{H}$ bond leads to the possibility that $\mathrm{Ge}-\mathrm{H}$ bonds may be broken in the material, particularly at higher growth temperatures which generally seem to be necessary for achieving the growth of the best material. In addition, there may be a greater density of microvoids in the material[16], leading to further non-homogeneity in the material. Also, from fundamental thermodynamics, an alloy is always going to have a greater degree of disorder than a single element system.

A particularly disturbing aspect of a- $(\mathrm{Si}, \mathrm{Ge})$ material is its tendency to become nonhomogeneous because of the chemistry of growth [17]. During plasma deposition, t he fundamental reaction that takes place in the plasma is probably the decomposition of silane and germane into silyl [SiH3] and germyl[GeH3] radicals [18]. Germyl is much heavier than silyl; therefore, its mobility on the surface is likely to be much lower than the mobility of silyl. An unavoidable consequence of this fact is that there is likely to be more clustering and less randomization of germyl radicals on the surface during growth. That is, a germyl radical is likely to stick to its local site rather than move around to find the best ( energy minimizing) site. A consequence of this fact is that there may be localized vertical and horizontal clusters of germanium forming in the material during growth. It is precisely to minimize such localized clustering that Sanyo found it necessary to grow a- $(\mathrm{Si}, \mathrm{Ge})$ at higher temperatures than a$\mathrm{Si}: H .[19]$. Unfortunately, such higher temperatures may tend to also introduce some broken Ge$\mathrm{H}$ bonds, and certainly, broken Ge-H2 bonds, some of which are inevitable at surfaces of internal voids.[17]

An alternative means of reducing clustering during growth would be to promote the movement of radicals on the surface during growth. Such increases in surface mobility can be achieved by using a bias voltage on the surface, as was shown by Dalal et al in 1985 [12]. Work by Professor Paul's group at Harvard also showed that a negative substrate bias during growth significantly improved the material properties[20]. An alternative means which has also been used to improve the material is heavy hydrogen dilution[19]. During heavy hydrogen dilution, in order to keep up the growth rate, one needs to increase the power level significantly, which increases the ion energies, and ion flux. Thus, either a direct dc bias, or an indirect increase in ion bombardment, both seem to favor the growth of a better quality a-(Si,Ge). 
Based on our previous work in this field, we recognized the value of controlled ion bombardment, and implemented it using our ECR reactor system. As shown earlier, the ECR reactor is a very good tool for controlling the flux of ions and radicals arriving at the surface. Also, the ion energies are generally lower than in a standard glow discharge reactor. Therefore, one should be able to obtain high quality films and devices in a-( $\mathrm{Si}, \mathrm{Ge})$ by carefully controlling the plasma processes in the ECR reactor. In this section, we present the results of our work in this field.

\section{II.2 Reactor system}

The basic reactor system has been described earlier and therefore will not be repeated. However, a few points about the plasma characteristics are worth mentioning.

1. The plasma potential, and plasma flux, both depend upon the pressure in the reactor. The higher the pressure, the lower the plasma potential and the lower the flux of ions arriving at the substrate. Fig. 2.1 shows this result for a He plasma.

2. The plasma potential depends upon the gas used. If Hydrogen is used, the potential is much lower than if $\mathrm{He}$ is used as the plasma gas. See Fig. 2.2

From these two results, then, one can conclude that by carefully choosing the plasma gas, and reactor pressure, one can control the flux and potential of ions arriving at the substrate. This fact will turn out to be of surprisingly great importance in producing the best quality a- $(\mathrm{Si}, \mathrm{Ge})$ materials and devices.

\section{II.3 Properties of Films Grown Using Helium}

We grew a series of a-( $\mathrm{Si}, \mathrm{Ge}): \mathrm{H}$ films using $\mathrm{He}$ as the plasma gas. The typical process conditions are in Table 2.1.

Table 2.1.

Typical processing conditions for a-(Si,Ge): $\mathrm{H}$ films using $\mathrm{He}$ as the plasma gas

$\begin{array}{ll}\text { He flow rate: } & 45 \mathrm{sccm} \\ \text { Silane flow rate } & 1.6 \mathrm{sccm} \\ 10 \% \text { Germane in } \mathrm{H} 2 \text { flow rate } & 1-10 \mathrm{sccm} \\ \text { Pressure } & 10 \mathrm{mT} \\ \text { Temperature } & 300-350 \mathrm{C} \\ \text { Power } & 60 \mathrm{~W}\end{array}$

The typical growth rates were found to be in the 1-2 A/sec range. Typical film thicknesses wee kept in the 1.0 micrometer range.

The electronic properties which were measured were:

Photo and dark conductivity

Activation energy

Subgap absorption and Urbach energy of valence band tails 


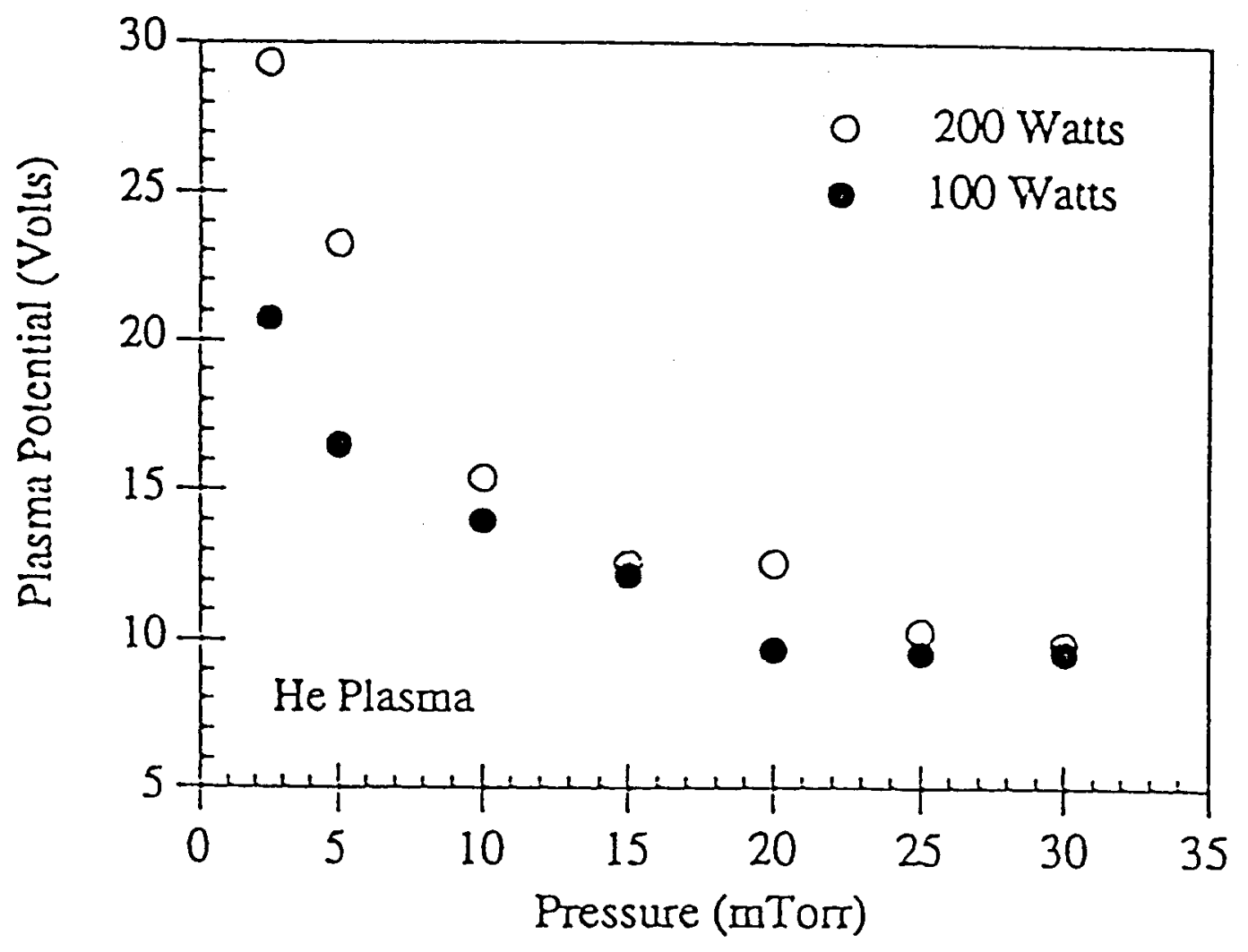

Fig. 2.1 Plasma potential vs. pressure for a He-ECR discharge at two power levels 


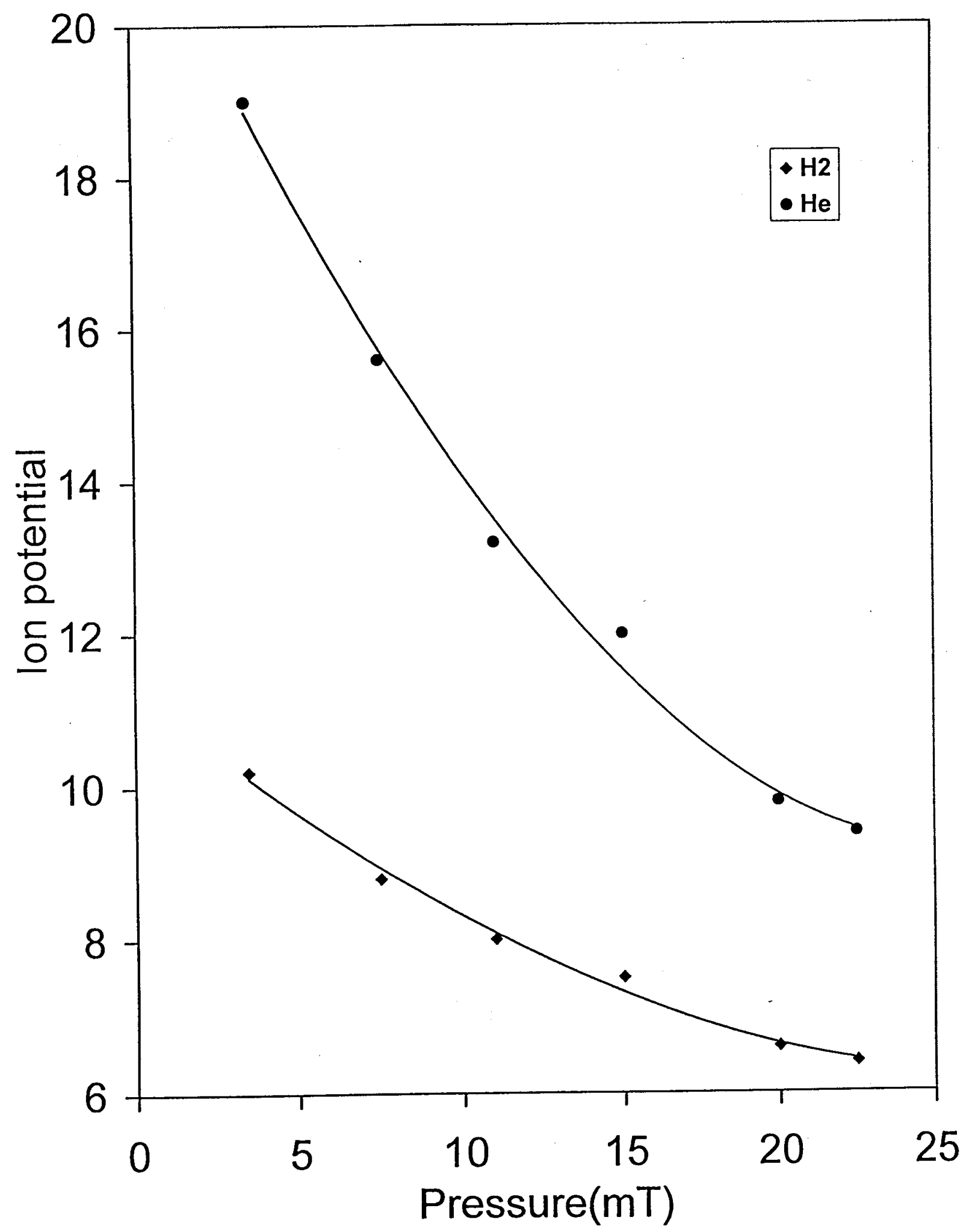

Fig. 2.2 Ion potentials in He and H ECR discharges 
The subgap absorption was measured using a two-beam photo-conductivity technique, with an ac probe beam and a dc beam to fix the positions of the quasi-Fermi levels.[21 ].

In addition to these, we also measured the $\mathrm{H}$ content of the films using FTIR spectroscopy.

These results have been published previously[23 ]. Here, we simply quote the more important results of our investigation into the properties of $\mathrm{He}-\mathrm{ECR}$ a- $(\mathrm{Si}, \mathrm{Ge})$ films.

1. The photo-to dark conductivity ratio is very high, $>10^{4}$ for films with bandgaps $>1.45 \mathrm{eV}$.

2. The Urbach energies are very low, about 45-50 meV, and they increase as the bandgap decreases.

3. Absorption coefficient, $\alpha$, measured at the shoulder of the subgap $\alpha(E)$ curve, , is low, in the range of $0.5 / \mathrm{cm}$ to $1.5 / \mathrm{cm}$, depending on the bandgap. A lower gap leads to a higher $\alpha$

From this section, we can conclude that the ECR deposited films, made with He dilution, are of a higher quality than comparable glow discharge produced films. But, all the data seem to indicate that as the Tauc gap decreases ( Ge content increases), the properties of the films do degrade.

In Fig. 2.3, we show the $\mathrm{H}$ content of the films, made using He or Hydrogen dilution. We plot the $\mathrm{H}$ content as a function of Tauc gap. A striking and surprising observation from this figure is that the He-ECR films have a significantly lower H content than comparable H-ECR films.

\section{II.4 Properties of films made using Hydrogen dilution}

A. Films made at low pressures $(10 \mathrm{mT})$

A series of films was grown using hydrogen dilution. Deposition conditions were similar to the ones reported in Table 1, except one had to use higher power levels, and the hydrogen flow rate was about $40-45 \mathrm{sccm}$. Note that Germane is already prediluted $10 \%$ in hydrogen. This fact means that the He-ECR films already had some small amount of hydrogen dilution. When we produce films with hydrogen dilution, the ratio of hydrogen to (silane+germane) increases to about 15:1.

In Fig. 24 and 2.5, we plot the results for photo and dark conductivities and their ratio as a function of Tauc gap. In common with the results reported earlier on He-ECR films, films with high photo-sensitivities can also be made using H-ECR.In Fig. 2.6, we plot the Urbach energies of these films as a function of Tauc gap. Once again, the Urbach energies are low, comparable to the energies reported earlier for He-ECR films. In Fig. 2.7, we plot the subgap absorption coefficient, $\alpha$, measured at the shoulder, as a function of Tauc gap. The values of $\alpha$ are fairly low, though they do increase as the bandgap decreases. The data on the $\mathrm{H}$ content of the films were shown earlier in Fig. 2.3.

From this section, we can conclude that at $10 \mathrm{mT}$, we can indeed produce good films using $\mathrm{H}$ dilution. 


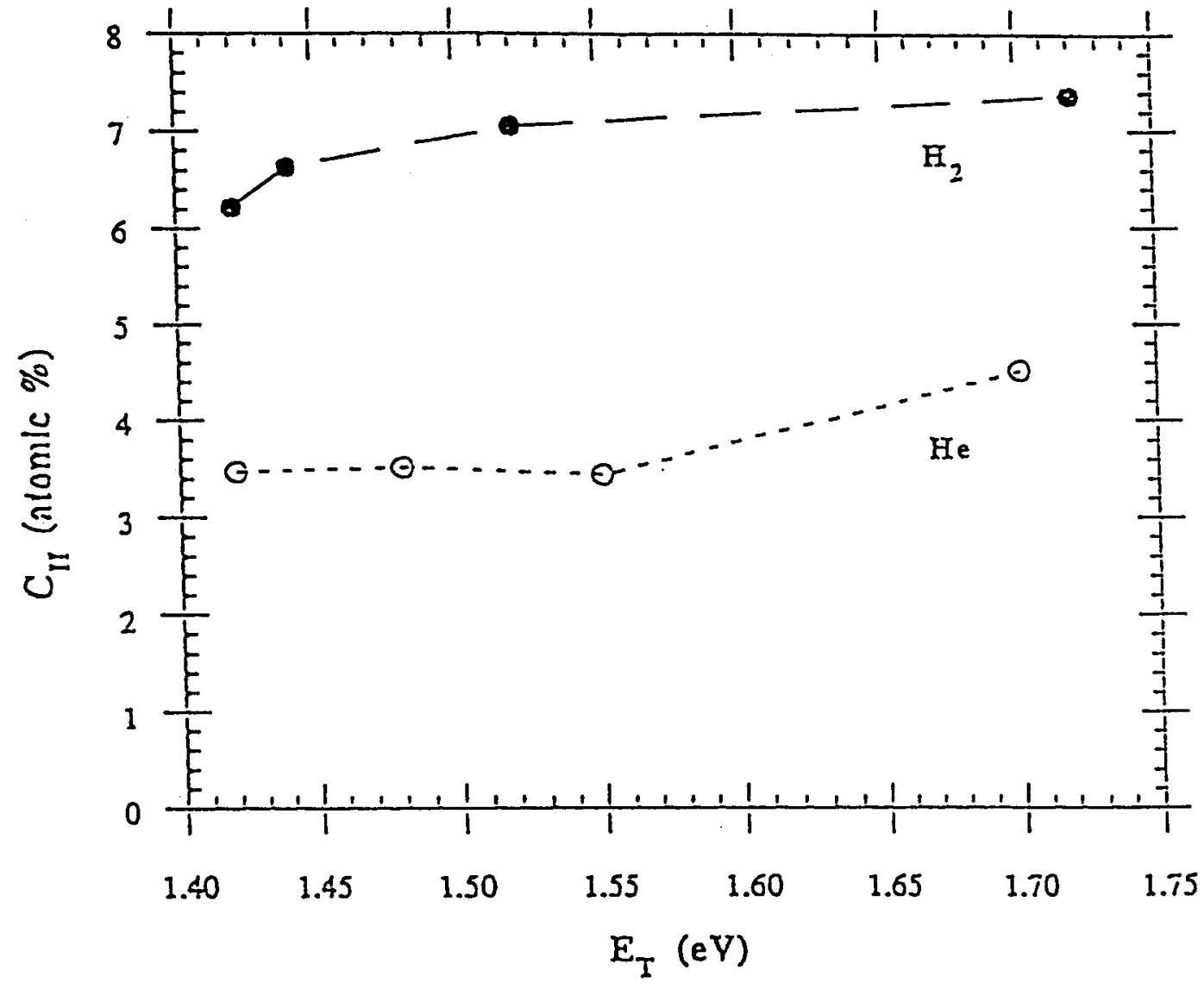

Fig. 2.3 Bonded $\mathrm{H}$ concentrations in a-(Si,Ge) films made with either $\mathrm{H}$ or $\mathrm{He}$ Dilution in an ECR reactor 


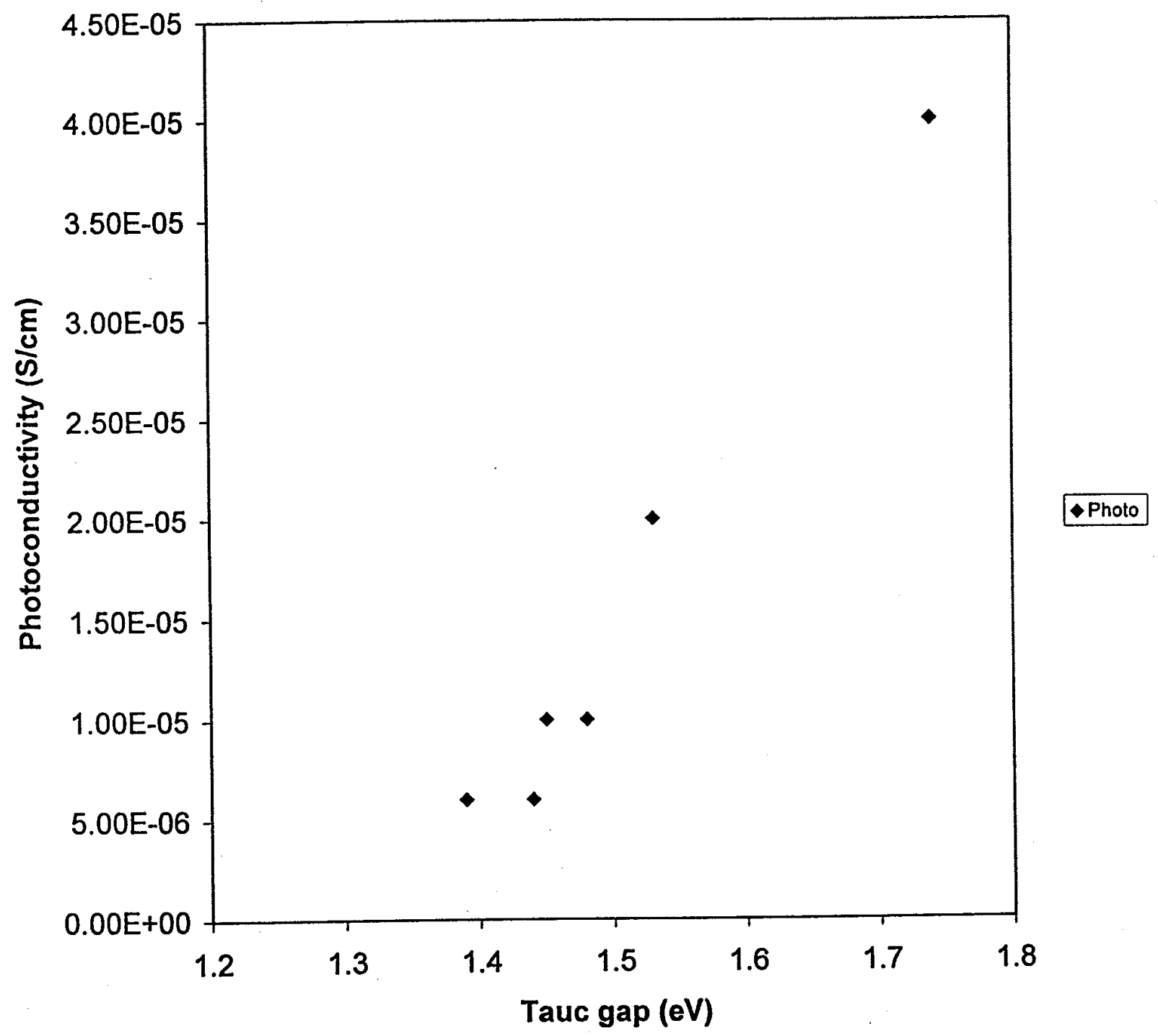

Fig. 2.4 Photoconductivity, measured under AM1.5 conditions, for a-(Si,Ge) films made using H-ECR process 


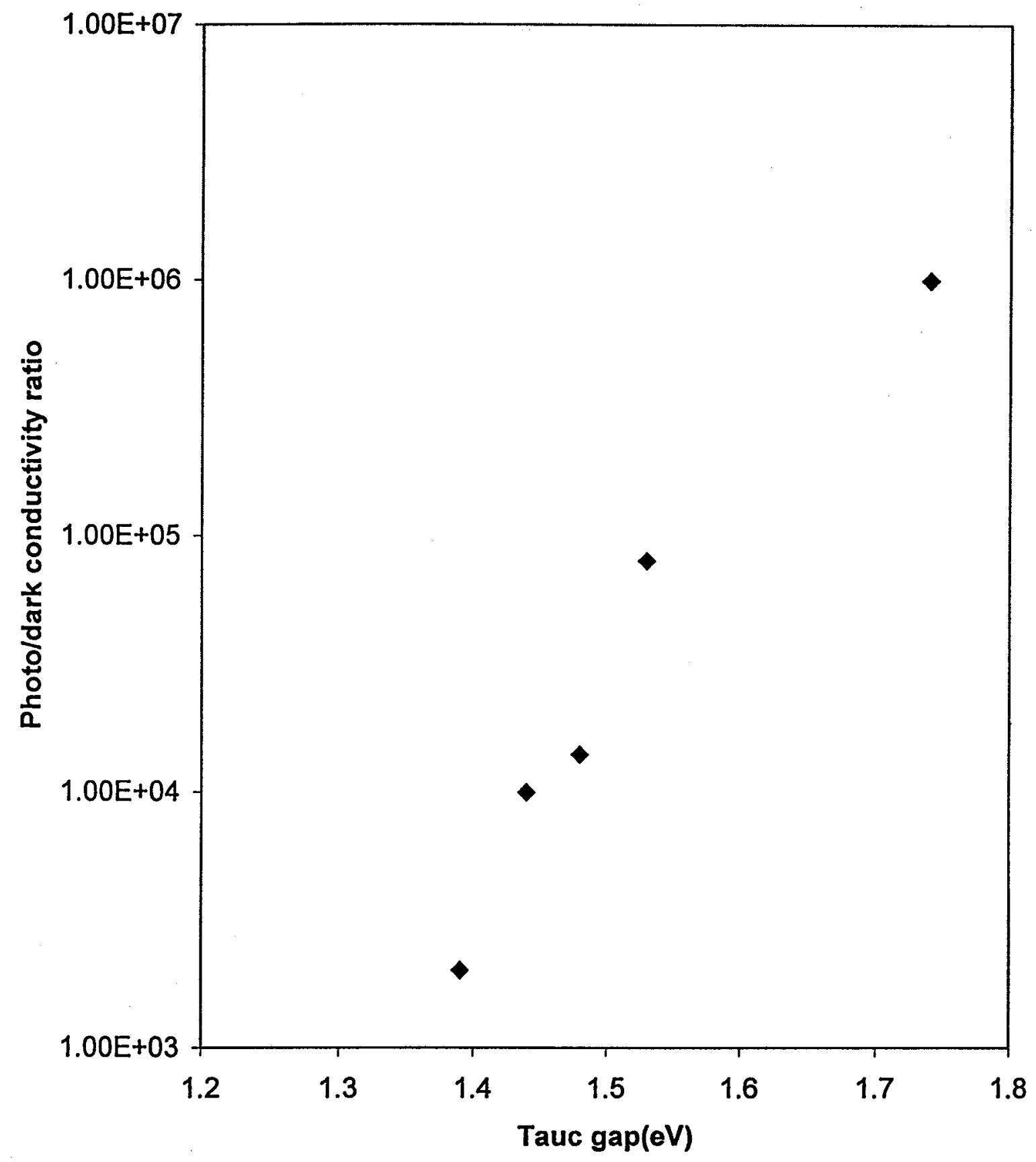

Fig. 2.5 Photo/dark conductivity ratio for H-ECR a-(Si,Ge) films as a function of Tauc gap 


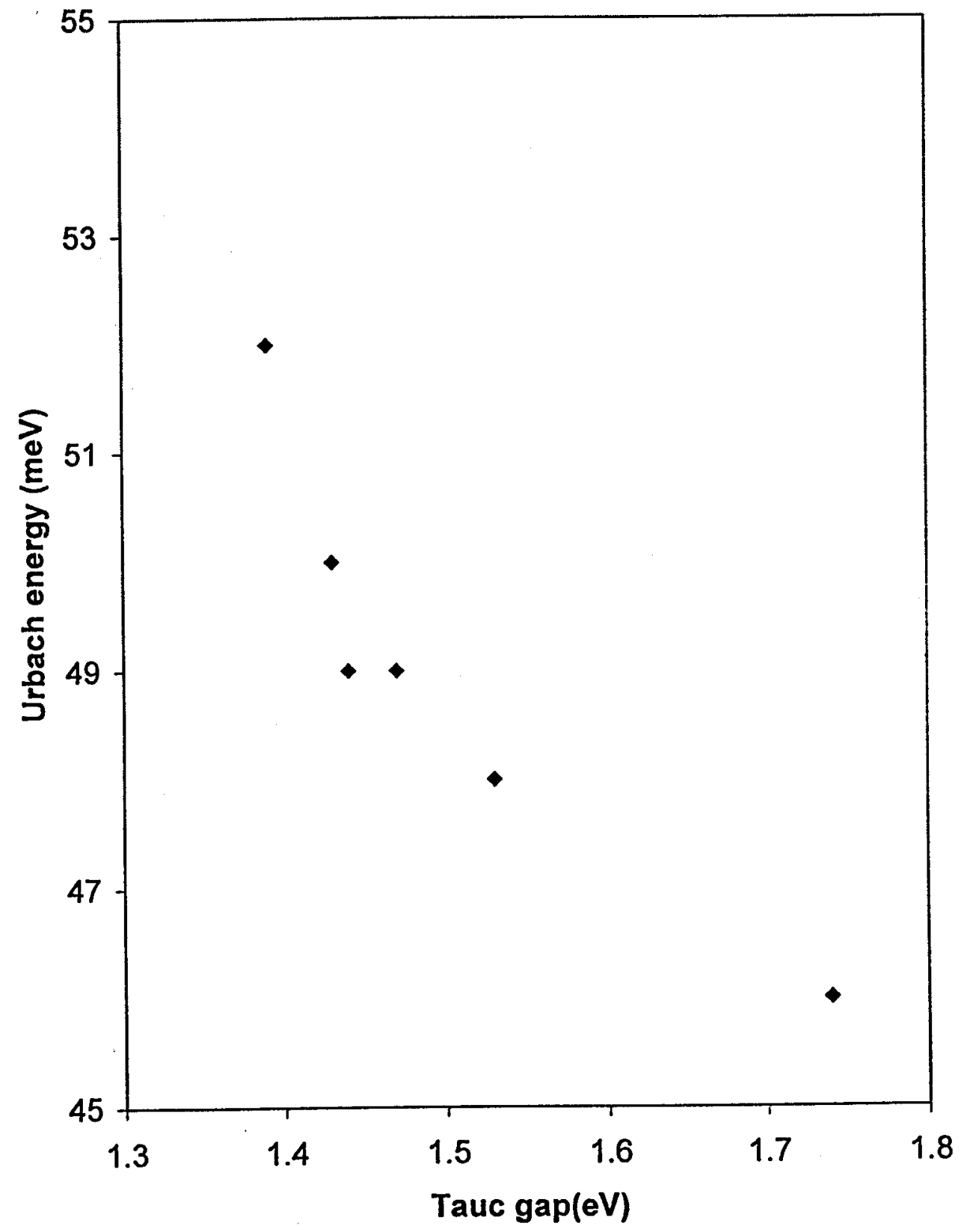

Fig. 2.6 Urbach energy vs. Tauc gap for H-ECR films 


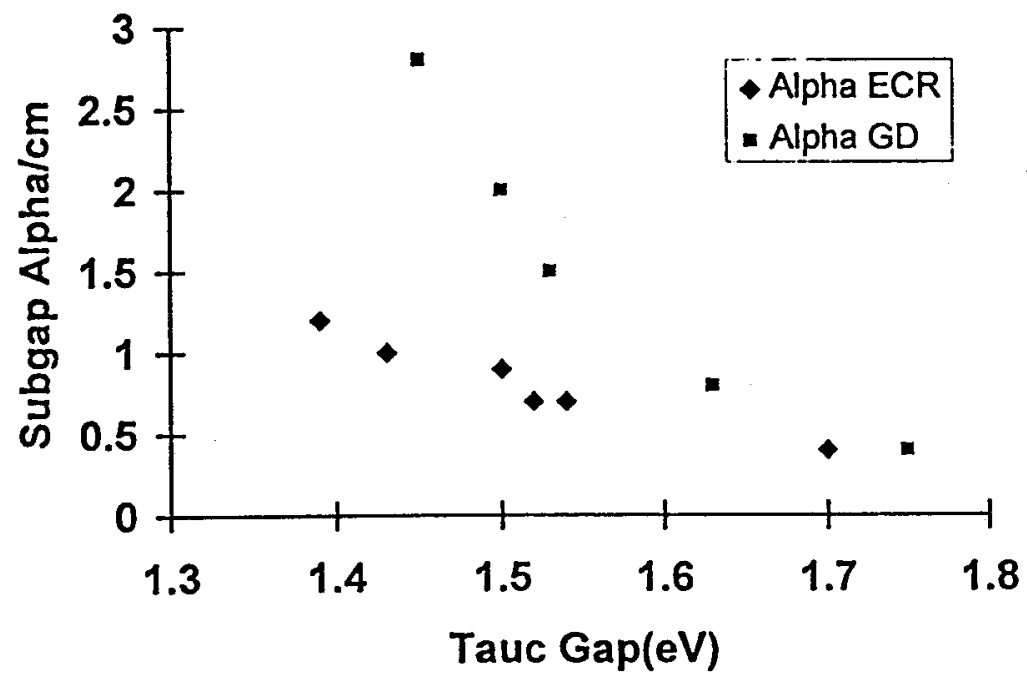

Fig. 2.7 Subgap alpha, measured at the shoulder, vs. Tauc gap for films made using H-ECR and glow discharge processes 


\section{B. Results on films grown at $15 \mathrm{mT}$}

We next decided to vary the pressure during deposition, keeping everything else constant. To our great surprise, we discovered that the results were dramatically different. from the films produced at $10 \mathrm{mT}$. In Fig. 2.8, we show the absorption curves for two films, one produced at $15 \mathrm{mT}$ and one at $10 \mathrm{mT}$, with the same silane/germane ratio in the gas phase, same temperature, same dilution ratio etc. Clearly, the film deposited at a higher pressure has a much lower bandgap. This is an astonishing result, which indicates that the growth chemistry depends upon the pressure in the reactor.

Based on the above result, we decided to grow a film at $6 \mathrm{mT}$, while keeping everything else the same as at 10 and $15 \mathrm{mT}$. We again got as slight change in bandgap [ See Fig. 2.9]indicating higher bandgap than at $10 \mathrm{mT}$, but not as dramatic a result as obtained at $15 \mathrm{mT}$. When we repeated these experiments at different temperatures, different silane/germane ratios etc., we always found similar results; namely that there was a small difference between depositions done at $6 \mathrm{mT}$ and $10 \mathrm{mT}$, but a large difference between depositions done at $10 \mathrm{mT}$ and $15 \mathrm{mT}$. In particular, the bandgap decreases significantly when depositions were done at higher pressures.

We next measured the Urbach energies and subgap $\alpha$ for films grown at different pressures as a function of Tauc gap. The results for Urbach energies of films grown at two different pressures are shown in Fig. 2.10 and for subgap $\alpha$ in Fig. 2.11. The results obtained from comparing the data for films grown at different pressures are striking. The films grown at low pressures are always better electronically ( lower Urbach energies, lower subgap $\alpha$ ) for the same Tauc gap.

From the results described in this section, we conclude that pressure during growth has a major effect on film properties, including the most fundamental of all, optical absorption and Tauc gap. The electronic properties of films grown at lower pressures are better. This is a very surprising result, quite unexpected and puzzling.

\section{$\underline{\text { Results on Helium-ECR films at higher pressures }}$}

Intrigued by the results obtained on H-ECR films, we decided to investigate He-ECR films at higher pressures. To our surprise, when we increased the pressure to 20 and $25 \mathrm{mT}$, nothing changed. The films had the same properties as films made at $10 \mathrm{mT}$. However, when we increased the pressure further to 30-35 $\mathrm{mT}$ range, the bandgap began to decrease, and film properties began to degrade, just as with H-ECR films. See Fig. 2.12 for absorption data on two He-ECR films, one made at $15 \mathrm{mT}$ and one at $35 \mathrm{mT}$.

So, here was a puzzle. The properties of H-ECR films depended critically upon the deposition pressure, even at lower pressures(e.g. $10 \mathrm{mT}$ ), whereas the properties of He-ECR films only depended on pressure at much higher pressure values (e.g. $35 \mathrm{mT}$ ). Clearly, something was changing in the plasma chemistry, and this change was different for a He plasma when compared with a $\mathrm{H}$ plasma. 


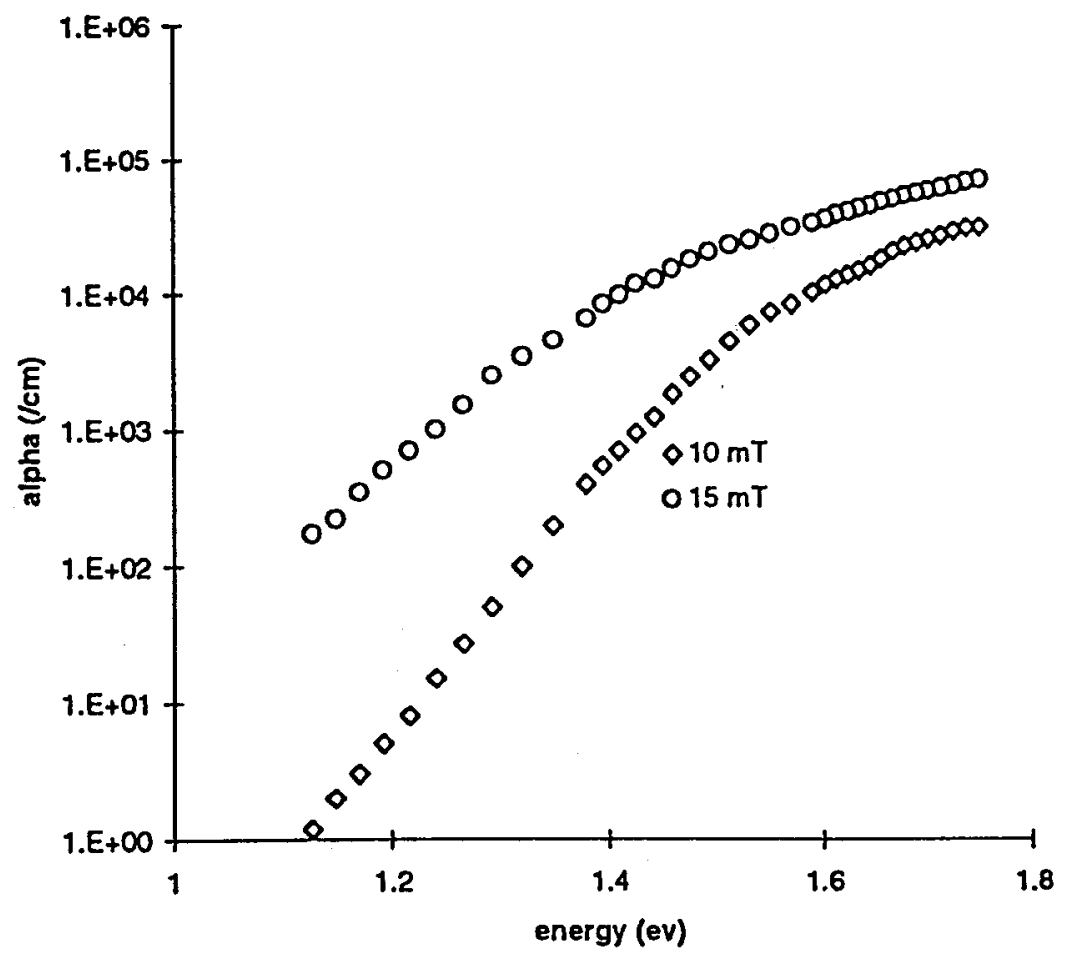

Fig. 2.8 Alpha vs. Energy curves for two films grown at different pressures. All other conditions of growth, including silane/germane ratios, were identical for the two films. 


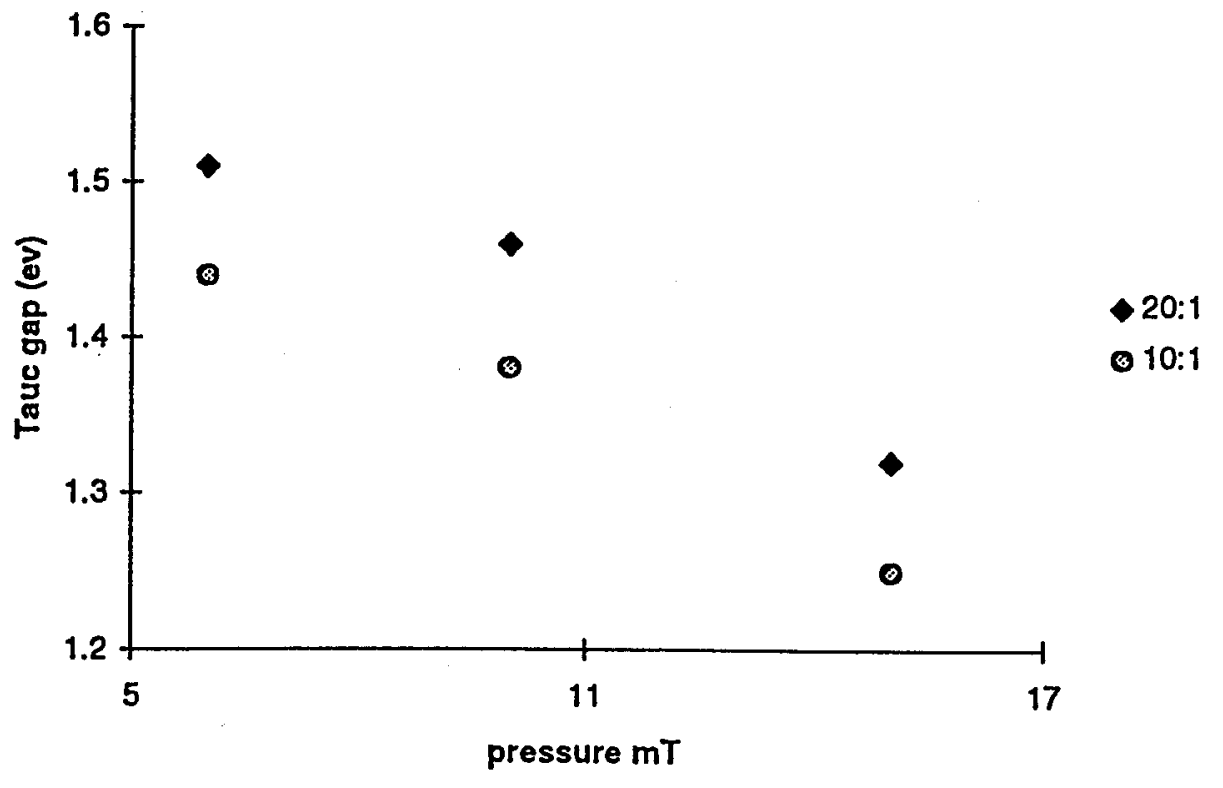

Fig. 2.9 Tauc gap vs. pressure for H-ECR films for two different silane/germae ratios 


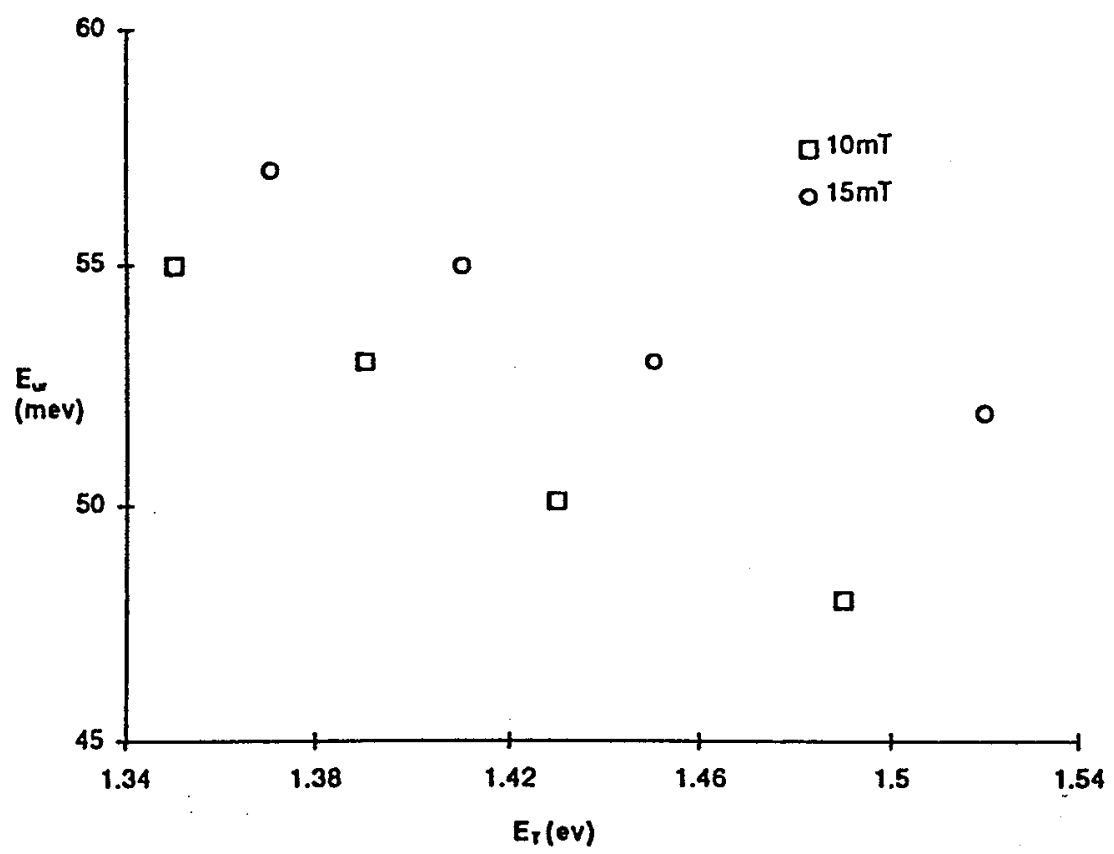

Fig. 2.10 Urbach energy of valence band tails vs. Tauc gap for films grown at two different pressures 


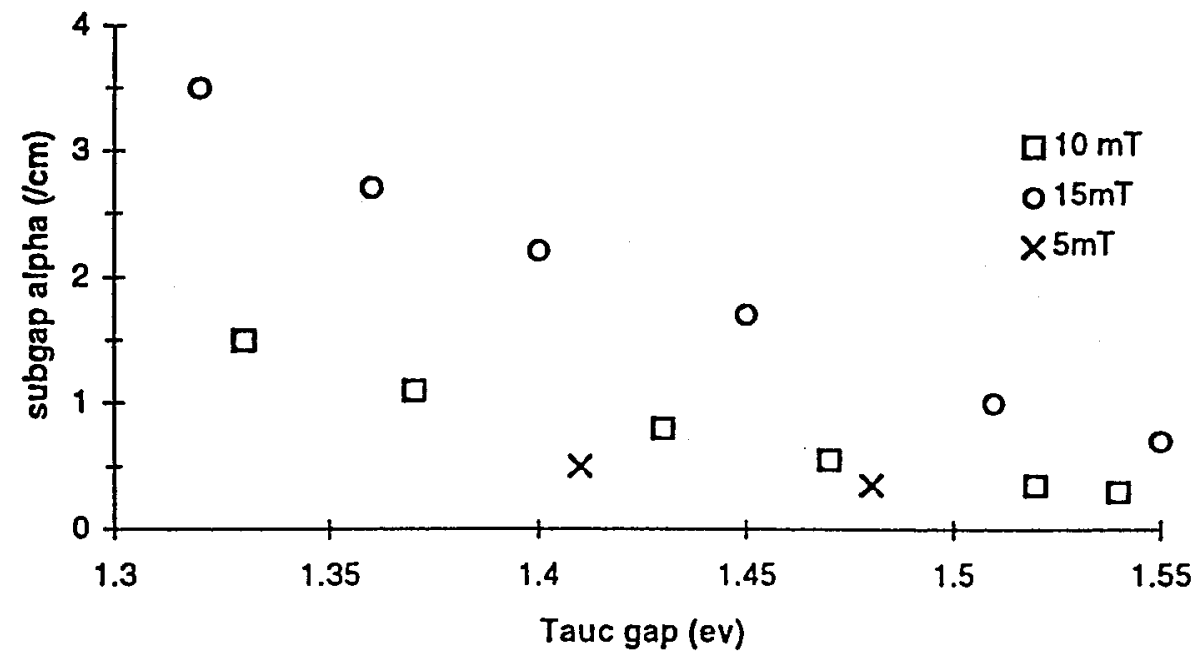

Fig. 2.11 Subgap alpha, measured at the shoulder, vs. Tauc gap, for films made at two different pressures 

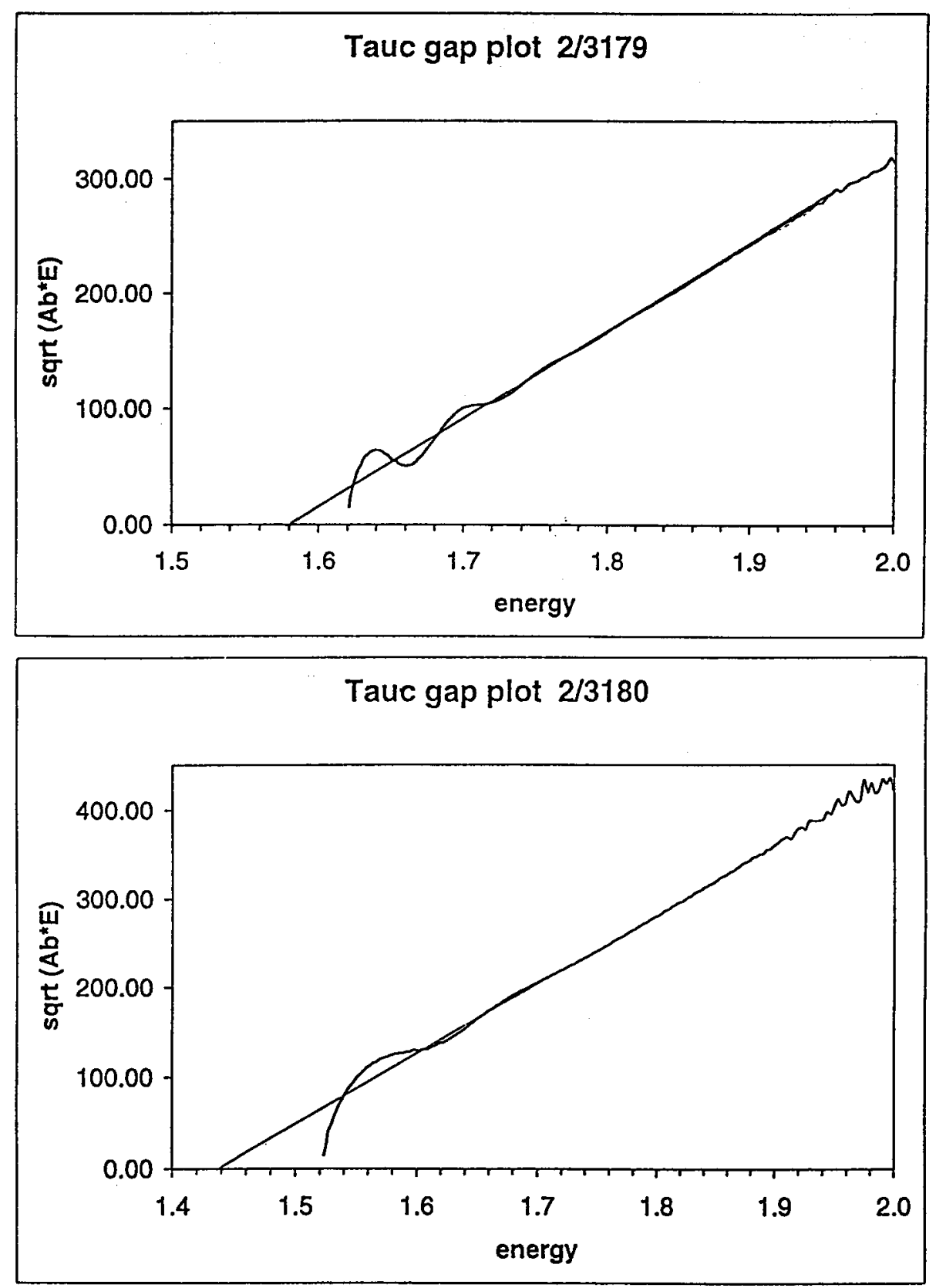

Fig. 2.12 Tauc curves for two films prepared at 15 and $35 \mathrm{mT}$ using He as the diluent gas. A lower gap is seen at higher pressures. 


\section{II.5 A Possible explanation for the pressure results}

A possible explanation for the pressure results can be found in the differences in plasma characteristics of He and Hydrogen plasma. From Fig. 2.1 and 2.2, we know that as the pressure decreases, the ion flux and ion energies increase for both $\mathrm{H}$ and He plasmas. Thus, looking at the hydrogen case first, perhaps the improvement in film properties can be explained by an increase in ion flux and energy impinging on the surface at lower pressures. From fundamental considerations of growth chemistry, as explained earlier, ion bombardment ought to help in improving film properties. The question of why the bandgap decreases, i.e.optical absorption increases, as pressure increases can be answered by postulating that at higher pressures, there is likely to be more clustering of atoms, because of reduced ion bombardment, and therefore, the effective bandgap decreases, compared with a uniform random alloy.

There still remains the question of why He-ECR produced films do not show such effects at lower pressures, but do at higher pressures. The answer can be postulated by comparing Fig. 2.1 and 2.2, where we show that a He plasma is much more energetic than a comparable $\mathrm{H}$ plasma. Therefore, one needs to go to much higher pressures before the ion bombardment in a He plasma becomes ineffective, and thereby, leads to poorer film bonding and properties. Also, one has to be mindful of the fact that He has 4 times the mass of hydrogen; therefore, ion bombardment by He is much more likely to transfer momentum efficiently to a germyl radical than ion bombardment by $\mathrm{H}$ is. Therefore, one would require a much lower ion energy in He before the ion bombardment becomes ineffective in transferring momentum to the radical on the surface.

Thus, a combination of higher mass and higher energies in a He plasma compared with a $\mathrm{H}$ plasma explain the differences in pressure effects seen between the two plasmas. This is a remarkable result, never seen before, and it opens up potential new avenues for improving film and device properties. Obviously, one next needs to study the influence of ion bombardment from molecules such as deuterium, Argon and xenon.

\section{II.6 Results on devices in a-(Si,Ge):H}

We have made substrate-type devices in a-( $\mathrm{Si}, \mathrm{Ge}): \mathrm{H}$. The device geometries are the same as described earlier for substrate-type a-Si:H devices. Two different types of devices were made: Single gap devices, and graded gap devices

\section{$\underline{\text { 1. Results on single gap devices. }}$}

The single gap devices were made using the following geometries, as shown in Fig. 2.13. The devices were of the type: stainless steel/n layer of a-Si/graded gap n-i buffer layer/i layer of a(Si,Ge)of one gap/graded i-p buffer layer/p a-(Si,C). The two buffer layers were of the following type:

i) n-i buffer layer: Graded gap from a-Si:H at the $\mathrm{n}$ interface to a-(Si,GE):H at the i layer interface.

ii) p-i buffer layer: Graded gap from a-( $\mathrm{Si}, \mathrm{Ge}): \mathrm{H}$ at the I layer interface to a-(Si,C):H at the $\mathrm{p}$ 
layer interface. If we did not have these two graded gap buffer layers, fill factors suffered.

The purpose of making these single gap devices was to measure hole mobility-lifetime products using quantum efficiency $(\mathrm{QE})$ spectroscopy. As explained earlier in the chapter on a-Si:H research, by measuring $\mathrm{QE}$ as a function of applied voltage for different wavelengths, one can estimate hole $\mu \tau$ products.

In Fig. 2.14, we plot the I(V) curves for two devices, each made using the same silane/germane ratios, but at different pressures. In common with the results on films, the device made at lower pressures certainly seems to have a lower bandgap, a fact that is confirmed using subgap quantum efficiency data. See Fig. 2.15. A QE curve shifting to lower energies indicates a lower bandgap.

In Fig. 2.16, we plot the hole $\mu \tau$ product vs. Tauc gap for devices made using different pressures. The Tauc gaps in devices were calculated using the subgap QE data, and then looking at the shift in QE curves. In common with the results on films, the devices made at lower pressures have higher $\mu \tau$ products.

Thus, we have confirmed, using device data, that pressure indeed has a profound influence on the properties of a- $(\mathrm{Si}, \mathrm{Ge})$ films and devices. The postulated reason is the increased ion bombardment at lower pressures.

Similar work on influence of pressure on He-produced devices is currently in progress.

\section{Results on graded gap devices}

We have also made some proof-of-concept graded gap devices in a-(Si,Ge):H. The design of these devices included a grading in bandgap over the middle $50 \%$ of the I layer of the device, so as to achieve a field assist for holes.[15 ]. This grading is in addition to the graded gap buffer layers at p-I and I-n interfaces, which were always necessary to optimize devices.

In Fig. 2.17, we show the I(V) curve for one of these devices, made using H-ECR process. The device had a top semitransparent $\mathrm{Cr}$ contact. The fill factor is decent $(0.66)$, and so is the open circuit voltage( 0.66$)$. The QE data for this device is shown in Fig. 2.18. Note that there is no back reflector in this device. The thickness of the i layer is about 0.2 micrometers. The bandgap of the lowest gap layer is about $1.50 \mathrm{eV}$.

Thus, we have shown that reasonable quality devices can be made in a-(Si,Ge):H using the ECR process. The unexpected result that pressure, presumably through ion bombardment, influences the device and film properties, is very interesting, and may allow us to optimize these materials and devices. 


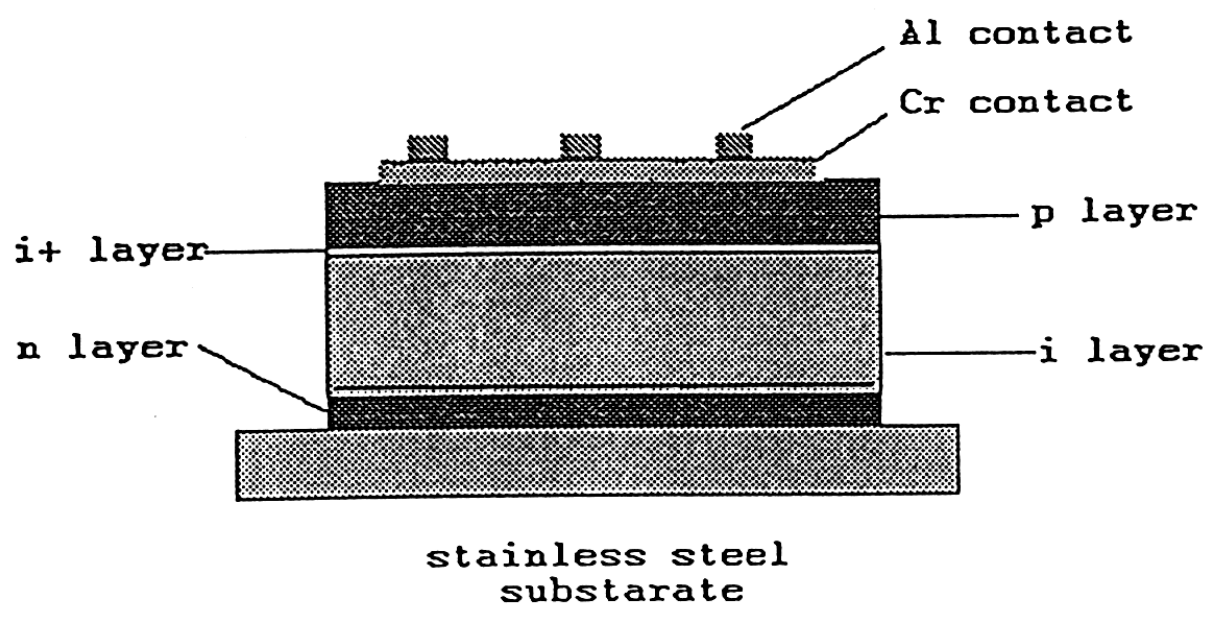

Fig. 2.13 Device geometry for a-(Si,Ge) cells 


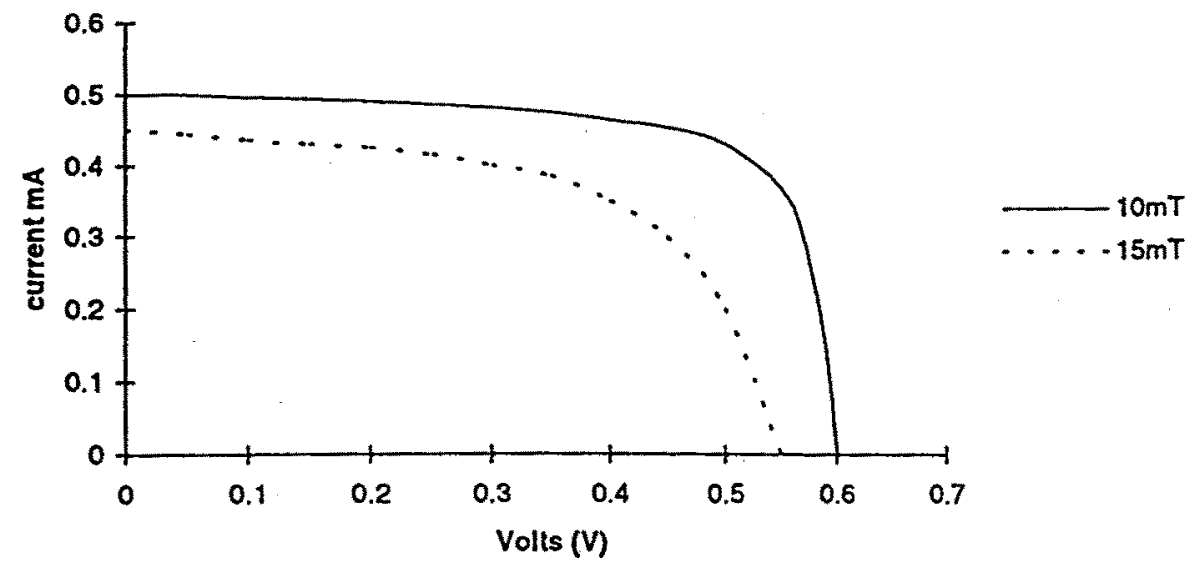

Fig. 2.14 I(V) curves for a-(Si,Ge) cells prepared at two different pressures.. 


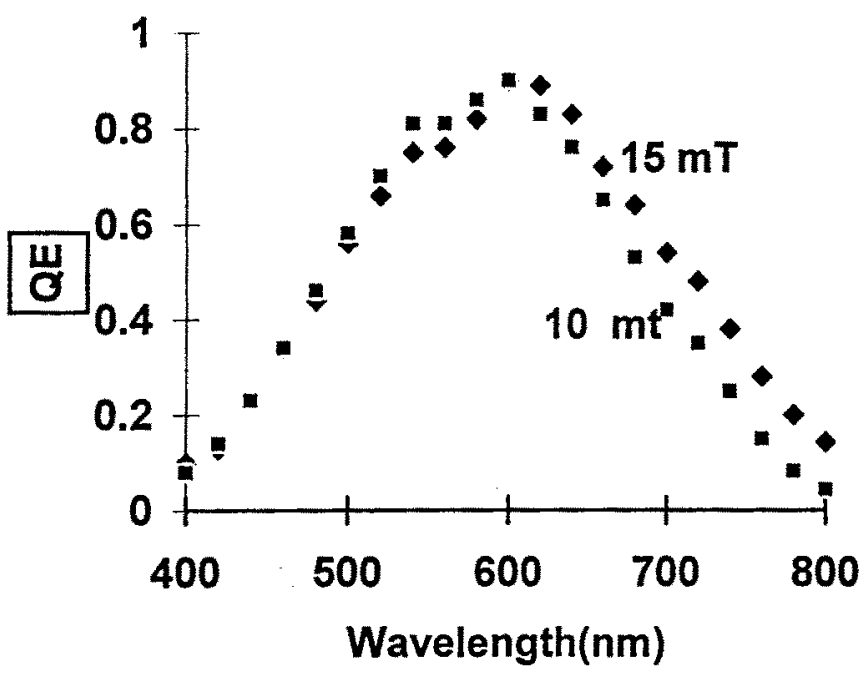

Fig. 2.15 QE data for a-(Si,Ge) cells prepared at two different pressures 


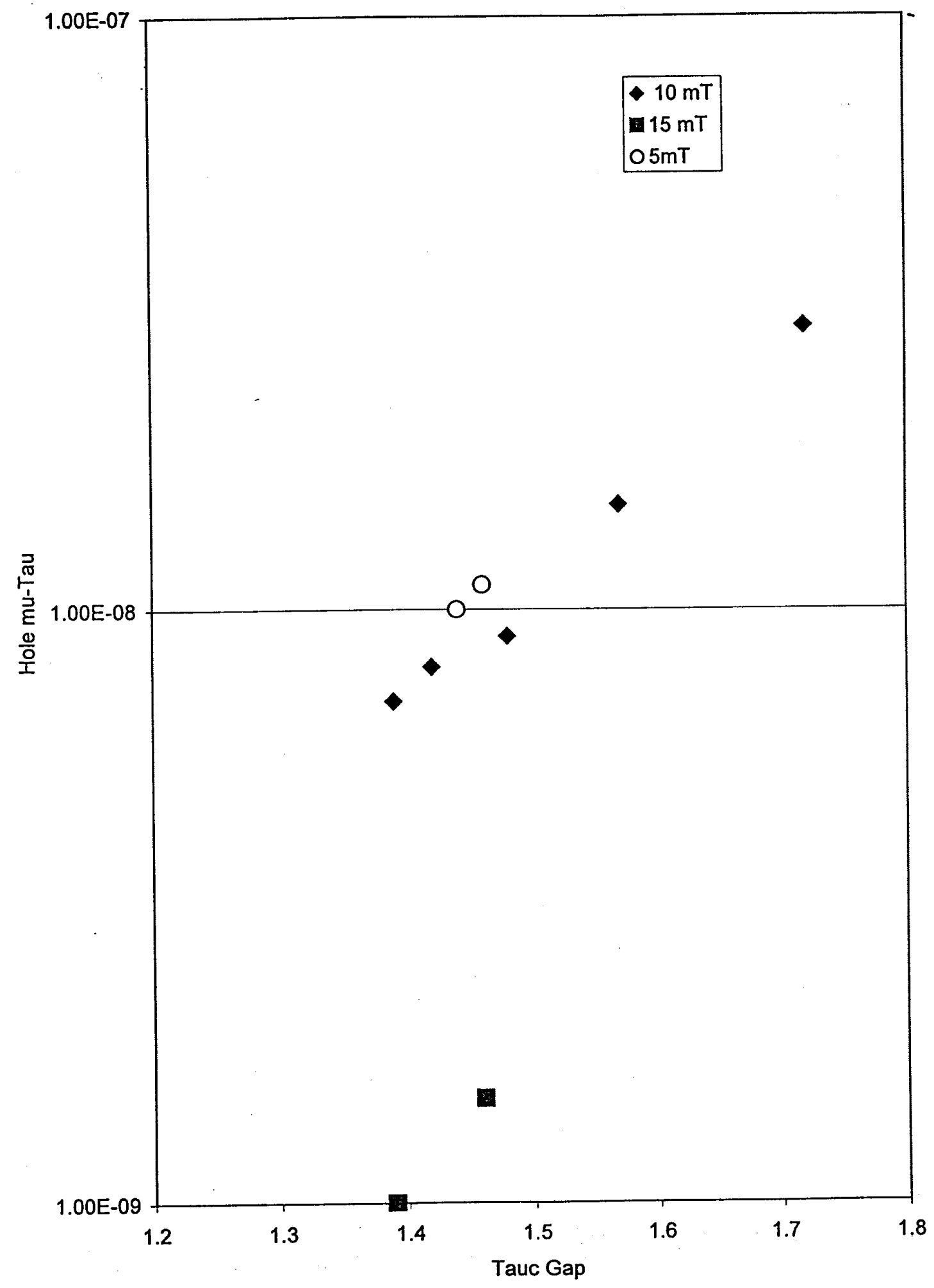

Fig. 2.16 Hole mobility-time products vs. Tauc gap measured in devices prepared at three different pressures 


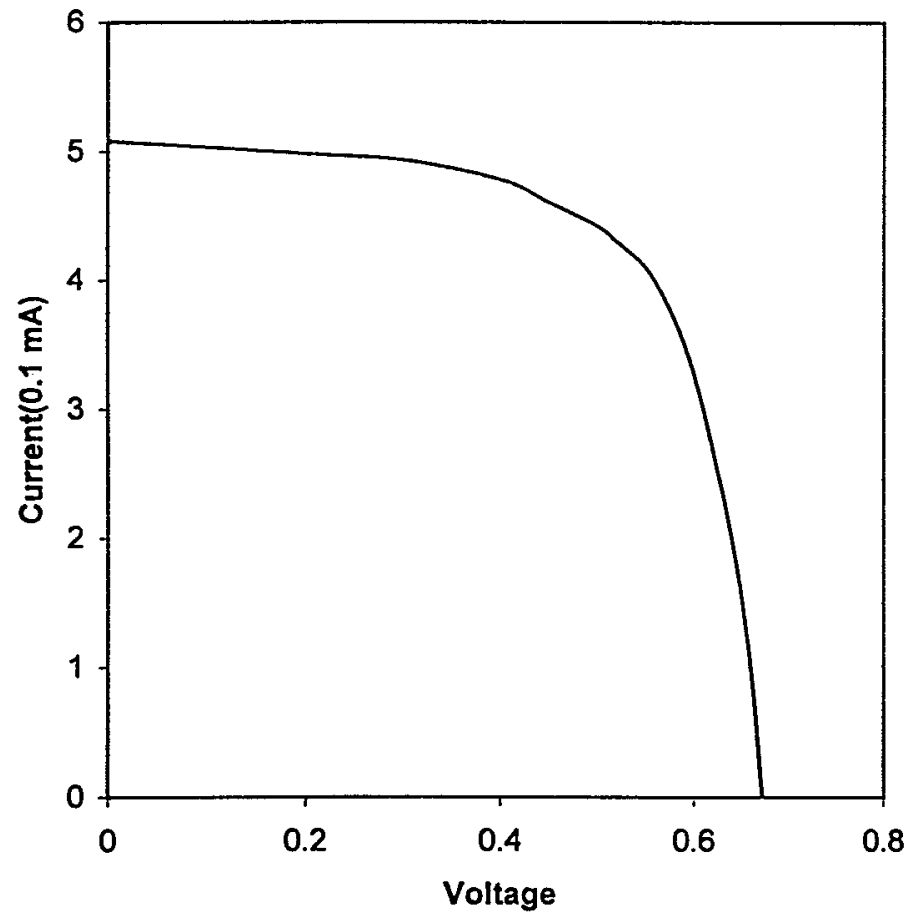

$\begin{array}{ll}\text { Fig. } 2.17 & \mathrm{I}(\mathrm{V}) \text { curve of graded gap cell }\end{array}$ 


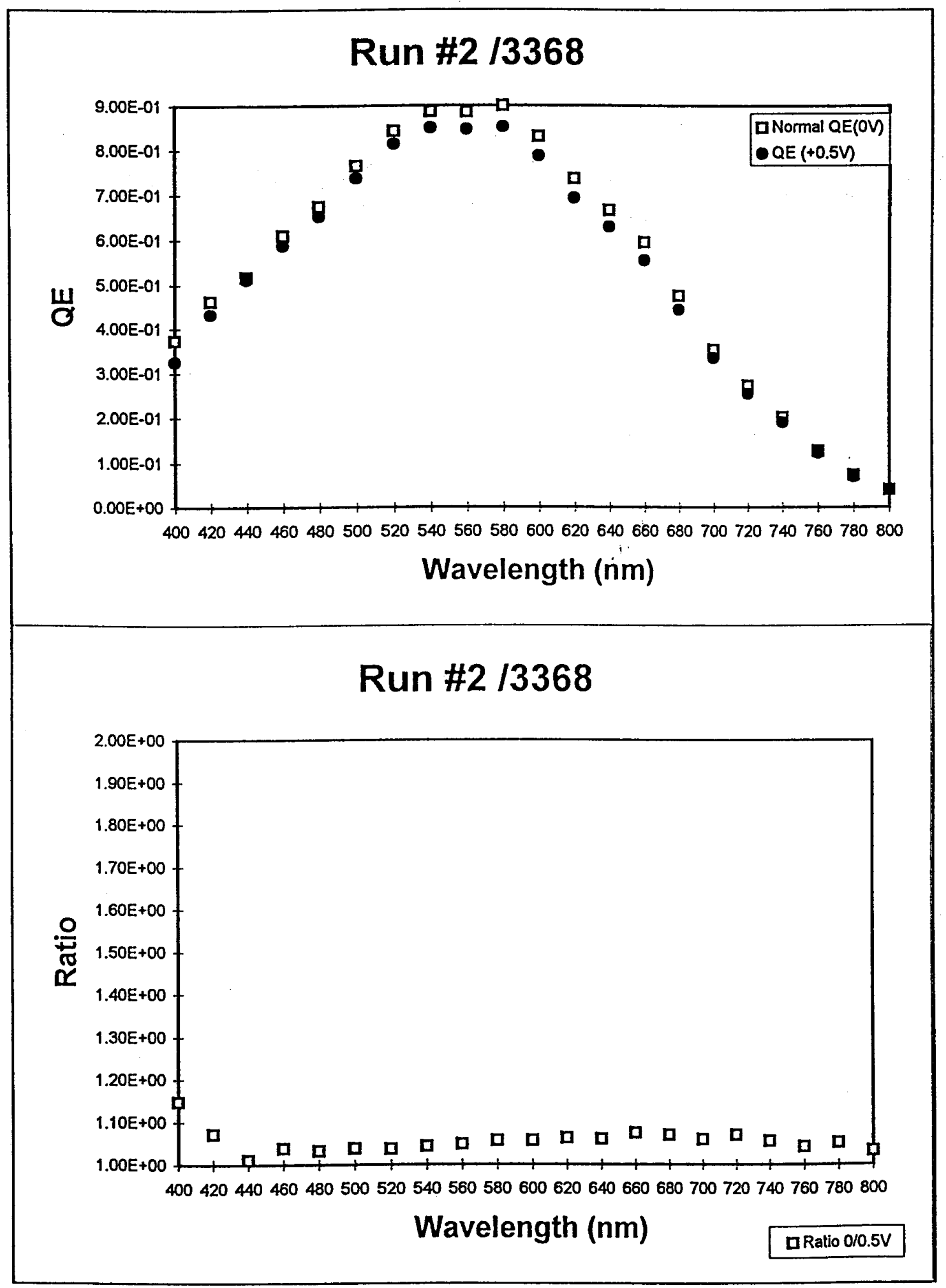

Fig. 2.18 $\quad$ QE and QE ratio curves for graded gap cell 


\section{II.7 Conclusions on a-(Si,Ge):H research}

In conclusion, we have shown that high quality materials and devices can be made in a$(\mathrm{Si}, \mathrm{GE}): \mathrm{H}$ using the ECR growth process. The ECR reactor is a fine chemical scalpel, which can be used to advantage to select the best processing conditions. It offers a degree of flexibility not available in standard glow discharge reactors, and we have used this flexibility to advantage to improve both materials and devices. The very unexpected, but self-consistent, result on the influence of pressure on film and device properties is potentially a very important discovery which can be used to enhance the materials and devices by combining other molecules, such as deuterium and Argon, and other conditions such as substrate bias, to produce the best films and devices. We do not know whether the improvements are due to ion energy, or due to increased momentum transfer to the radicals during growth. It is usually found that ion bombardment per se is not generally beneficial for improving the quality of thin films[22], but momentum transfer may be. During the next contract, we plan to systematically separate these two effects. The potential impact of this work will be to improve the quality of the low gap a-( $\mathrm{Si}, \mathrm{Ge}): \mathrm{H}$ material which is used in a multi-junction cell. 


\section{Publications resulting from this work}

Much of the work done during this contract has been published, thereby fulfilling one of the requirements of the contract. The publications which resulted from this work are:

V. L. Dalal, T. Maxson and Kay Han, " Significant improvements in stability of a-Si:H single and tandem junction solar cells made using ECR plasma deposition", J. Non-Cryst.

Solids,227,1257(1998)

T. W. F. Russell, V. L. Dalal, R. Gay and S. Guha, "Design of critical experiments for scale-up", Prog. In Photovoltaics, 5, 353(1997)

V. L. Dalal, S. Kaushal and R. Girvan,, "Improvements in stability of a-Si:H solar cells", J. Noncrystalline Solids, 198-200, 1101(1996)

S. Kaushal, V. L. Dalal and J. Xu, "Growth of high quality a-(Si,Ge):H films using low pressure remote ECR discharge, J. Non-Cryst. Solids, 198-200, 563(1996)

S. DeBoer, V. L. Dalal, R. Bartel and G. Chumanov, "Low temperature epitaxial growth of Si films using high vacuum ECR plasma deposition”, Appl. Phys. Lett., 66, 2528(1995)

V. L. Dalal, T. Maxson and S. Haroon, "Influence of plasma chemistry on properties of a-(Si,Ge) devices", Proc. MRS, $\underline{507}, 441(1998)$

K. Erickson and V. L. Dalal, "Preparation and properties of microcrystalline ( $\mathrm{Si}, \mathrm{Ge})$ on plastic substrates" , Proc. of MRS, 507, 987(1998)

V. L. Dalal, S. Haroon and T. Maxson, "Influence of plasma chemistry on the properties of a( $\mathrm{Si}, \mathrm{Ge})$ solar cells", Proc. of $2^{\text {nd. }}$. World Conference on Photovoltaic Solar Energy Conversion, p.865(1998)

V. L. Dalal, T. Maxson, and K. Han "Properties of a-Si and a-(Si,Ge):H solar cells prepared using ECR deposition", Proc. of $26^{\text {th }}$. IEEE Photovolt. Spec. Conf, p. 695(1997)

V. L. Dalal, T. Maxson, R. Girvan and S. Haroon, "Stability of single and tandem junction a-Si solar cells prepared using ECR deposition”, Proc. of Matl. Res. Soc., 467, 813(1997)

K. Erickson and V. L. Dalal, "Growth of microcrystalline $\mathrm{Si}: \mathrm{H}$ and $(\mathrm{Si}, \mathrm{Ge}): \mathrm{H}$ films on polyimide substrates using ECR deposition techniques", Proc. of Mater. res. Soc., 467, 409(1997)

V. L. Dalal, S. Kaushal, T. Maxson, R. Girvan and A. Boerner, "Stability properties of a-Si and a-(Si,Ge):H films and devices deposited using remote ECR techniques", Proc. of Amer. Inst. of Phys.,Vol. 394, (Ed. Ed Witt et al), p. 33(1997). 
V. L. Dalal, S. Kaushal, R. Girvan, S. Hariasra and L. Sipahi, "Improved stability in a-Si solar cells", Proc. of $25^{\text {th }}$. IEEE Photovolt. Spec. Conf.,p. 1069(1996)

V. L. Dalal, S. Kaushal, L. Sipahi, S. Hariasra and R. Girvan, " Properties of substrate type a-Si devices prepared using ECR deposition", Proc. of Mater .res. Soc., Vol. 420 ，39(1996)

V. L. Dalal and S. Kaushal, E. X. Ping, J. Xu, R. Knox and K. Han, "Microcrystalline and mixed-phase Si:H: Preparation, properties and potential for devices", Proc. of Mater. Res. Soc. $\underline{377}, 137(1995)$

S. Deboer and V. L. Dalal, "Preparation and properties of high quality Si films grown using ECR plasma beam deposition", Proc. of $24^{\text {th }}$. IEEE Photovolt. Spec. Conf.,p.1258(1994)

V. L. Dalal, S. Kaushal, J. Xu and K. Han, " Critical review of growth and properties of a(Si,Ge):H", Proc. of $24^{\text {th }}$. IEEE Photovolt. Spec. Conf., p. 464(1994)

W. Luft, H. M. Branz, V. L. Dalal, S. Hegedus and E. Schiff "Progress in a-Si PV technology", Proc. of Amer. Inst. of Physics, Vol. 353, 81(1995) 


\section{Graduate Student Education in Photovoltaic Science and Technology Resulting From}

This Work

The following graduate students were educated in PV science and technology partly under this program.

Ph.D.

S. DeBoer

S. Kaushal

E. X. Ping

M.S.

T. Maxson

K. Erickson

S. Haroon

In addition to the above, the following graduate students are currently doing research in part on this project:

J. Herrold - cost shared by EE department

R. Estwick - cost shared by EE department

H. Sathwane

Xi Huang

Zhiyang Zhou

B. Oliver

$\mathrm{Vu}$ Anh Vu - cost shared by EE department

$\underline{\text { Undergraduate students }}$

About 10 undergraduate students did research on this project. Some of these were paid for by NSF under a REU grant to Iowa State University. 


\section{V.References}

1. V. L. Dalal, Final Report, NREL XG 1100638.

2. V. L. Dalal, E. X. Ping, S. Kaushal, M. Bhan, and M.Leonard, Appl. Phys. Lett., $\underline{64}$, 1862(1994)

3. V. L. Dalal, M. Leonard and G. Baldwin, J. Non-Cryst. Solids, 164-166, 71(1993)

4. A. Gallagher, J. Appl. Phys., 60, 1369(1986)

5. M. Kushner, J. Appl. Phys., 63, 2352(1988)

6. S. Jones et al, Proc. Mater. res. Soc., 297, 815(1993)

7. L. Yang and L. F. Chen, Proc. of MRS, 336, 669(1994)

8. E. Srinivasan and G. Parsons, Proc. of MRS, 467, 501(1997)

9. V. L. Dalal, M. Leonard, J. F. Booker and A. Vaseashta, Proc. of $18^{\text {th }}$. IEEE Photovolt. Spec. Conf., 847(1985)

10. V. L. Dalal, S. Kaushal and R. Girvan, J. Non-crystalline Solids, 198-200, 1101(1996)

11. J. Yang et al, Proc. of $26^{\text {th }}$. IEEE Photovolt. Spec. Conf., 563(1997)

12. V. L. Dalal, J. F. Booker and M. Leonard, Proc. of Mat'l Res. Soc., $\underline{49}$, 145(1985)

13. C. M. Fortmann, Proc. of MRS, $\underline{192}$, 27(1990)

14. P. A. Morin et al, Proc. MRS, 258, 523(1992)

15. V. L. Dalal and G. Baldwin, Proc. of $23^{\text {rd }}$. IEEE Photovolt. Spec. Conf., 1037(1993)

16. S. Jones et al, Proc. of MRS, 297, 815(1993)

17. V. L. Dalal, S. Kaushal, T. Maxson, R. Girvan and A. Boerner, Proc. of Amer. Inst. of Phys.,Vol. 394, (Ed. Ed Witt et al), p. 33(1997).

18. M. Kushner, J. Appl. Phys. 62, 2803(1987)

19. T. Kinoshita et al, Proc. of $14^{\text {th }}$. European PVSEC (1997)

20. P. Wickboldt et al, J. Non-Cryst. Solids, 198-200, 567(1996)

21. S. Kumar et al, J. Non-Cryst. Solids, 114, 316 (1989)

22. S. Deboer et al, Appl. Phys. Lett., 66, 2528(1995)

23. S. Kaushal and V. L. Dalal, J. Non-Cryst. Solids, 198, 563(1996) 


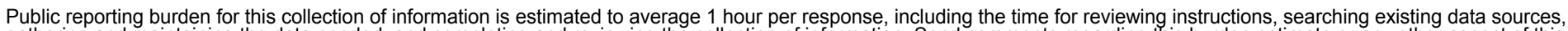

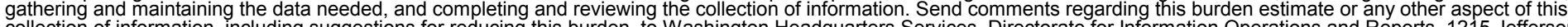

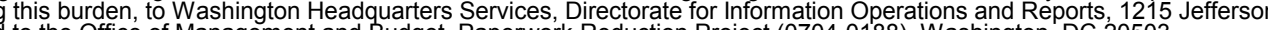
Davis Highway, Suite 1204, Arlington, VA 22202-4302, and to the Office of Management and Budget, Paperwork Reduction Project (0704-0188), Washington, DC 20503.

\begin{tabular}{|l|l|l|}
\hline 1. AGENCY USE ONLY (Leave blank) & $\begin{array}{l}\text { 2. REPORT DATE } \\
\text { September } 2000\end{array}$ & 3. REPORT TYPE AND DATES COVERED \\
\hline
\end{tabular}

4. TITLE AND SUBTITLE

Comprehensive Research on Stability of Amorphous Silicon and Alloy Materials and Devices

6. AUTHOR(S)

V.L. Dalal, K. Han, T. Maxson, R. Girvan, S. Kaushal, S. DeBoer, E. Ping, and S. Haroon

5. FUNDING NUMBERS

C: XAN-4-13318-08

TA: PV005001

7. PERFORMING ORGANIZATION NAME(S) AND ADDRESS(ES)

Iowa State University

8. PERFORMING ORGANIZATION REPORT NUMBER

Ames, Iowa

9. SPONSORING/MONITORING AGENCY NAME(S) AND ADDRESS(ES)

National Renewable Energy Laboratory

1617 Cole Blvd.

Golden, CO 80401-3393

10. SPONSORING/MONITORING AGENCY REPORT NUMBER

NREL/SR-520-28989

\section{SUPPLEMENTARY NOTES}

NREL Technical Monitor: Bolko von Roedern

12a. DISTRIBUTION/AVAILABILITY STATEMENT

National Technical Information Servce

12b. DISTRIBUTION CODE

U.S. Department of Commerce

285Port Royal Road

Springfield, VA 22161

13. ABSTRACT (Maximum 200 words) In this report, we describe the work done to improve the material and device properties of a-Si:H and a(Si,Ge):H alloys prepared using electron cyclotron resonance (ECR) plasma deposition and to understand the growth chemistry. Major results were obtained in the following areas: 1) Influence of plasma chemistry on properties and stability of a-Si:H single-junction solar cells; 2) Fabrication of good-quality tandem-junction cells. We made tandem-junction a-Si/a-Si cells with excellent voltages and fill factors using the H-ECR process; 3) Growth of high-quality a-(Si,Ge):H films using the ECR deposition process; 4) Fabrication of single-junction devices in a-(Si,Ge):H for diagnosing the material; and 5) Graded-gap cells in a-(Si,Ge):H. Good devices were produced using a gradedgap I-layer. In summary, the most important finding from our research has been that plasma chemistry plays a very important role in determining the properties of the materials, particularly the properties of the a-( $\mathrm{Si}, \mathrm{Ge}): \mathrm{H}$ alloy system. Even in a-Si:H, plasma chemistry plays a role in determining stability. This result suggests that by deliberately changing the chemistry of deposition, one may be able to further improve the a- $(\mathrm{Si}, \mathrm{Ge}): \mathrm{H}$ materials system and make its properties comparable to the properties of a-Si:H. The ECR reactor has proved to be a very useful chemical tool, with excellent control over growth chemistry.

14. SUBJECT TERMS

photovoltaics; a-Si materials and devices; ECR plasma deposition; single-junction solar cells; tandem-junction cells; graded-gap cells; plasma chemistry; electron cyclotron resonance

15. NUMBER OF PAGES

16. PRICE CODE

17. SECURITY CLASSIFICATION OF REPORT Unclassified
18. SECURITY CLASSIFICATION OF THIS PAGE Unclassified
19. SECURITY CLASSIFICATION OF ABSTRACT

Unclassified
20. LIMITATION OF ABSTRACT

UL 